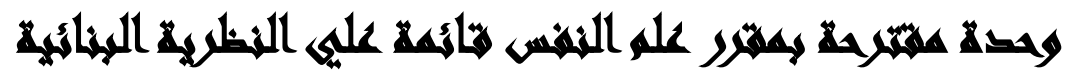

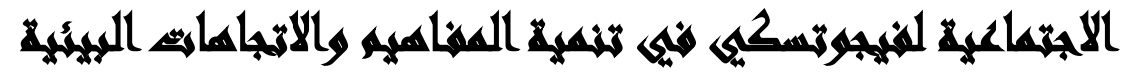

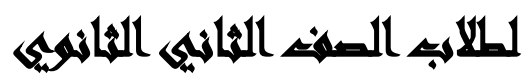

\section{$[r \leqslant]$}

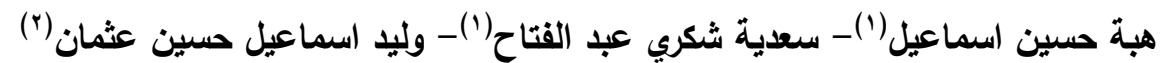
() كلية البنات، جامعة عين شمس r) وزارة التربية والتعليم

\section{المستخلص}

تهدف الدراسة الراهنة إلي استقصاء فعالية وحدة مقترحة بمقررعلم النفس قائمة علي

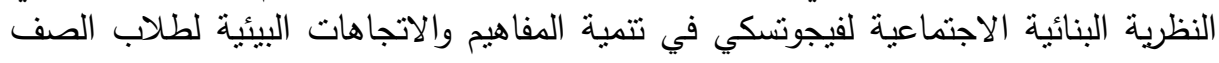

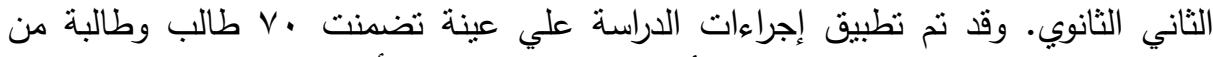

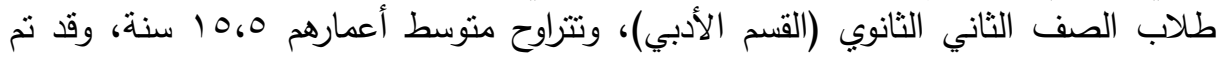

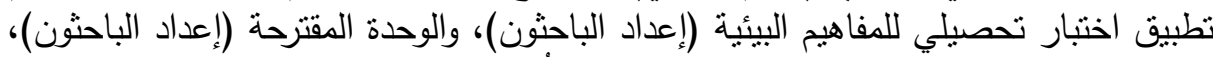

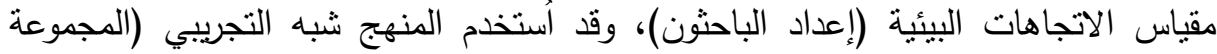
التجريبية الواحدة). - اتهات

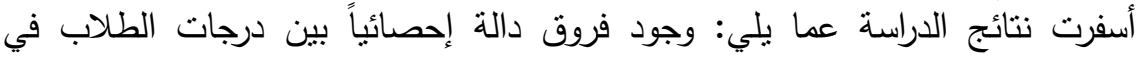
القياسين القبلي والبعدي للاختبار التحصيلي بمستوياته الثناثة (التذكر - الفهر - التطبيق)

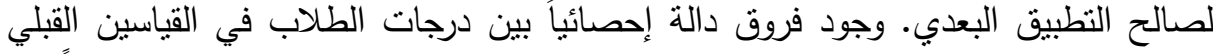

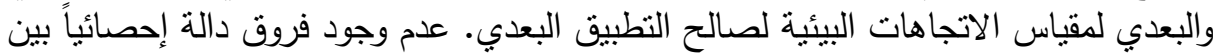

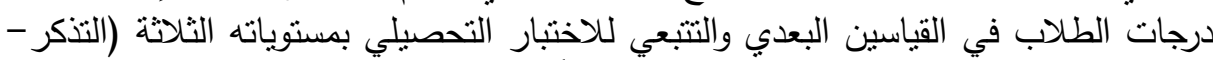

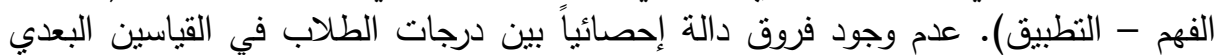
والتتبعي لمقياس الاتجاهات البيئية.

\section{المهبـهام}

إزاء الاهتمام المنزايد بالبيئة ومشكلاتها ، بدأت العديد من دول العالم وضع برامج

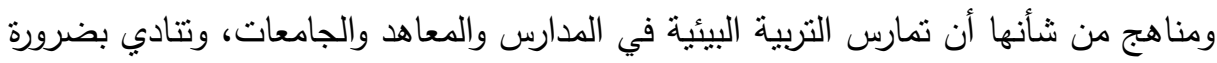
إدخال التربية البيئية على أسس سليمة وصحيحة ضمن المقررات الدراسية للمدارس، فالمحيط

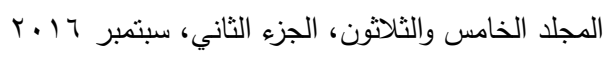


الذي يعيش الانسان فيه ويستمد منه كل مقومات حياته،أصبح يتعرض للإنتهاك والإستنزاف بصورة كبيرة.على الرغم من الإهتمام الكبير الذي حظيت به برامج التربية البيئية ومناهجها

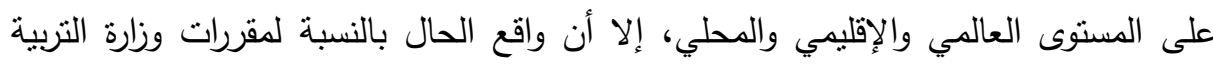

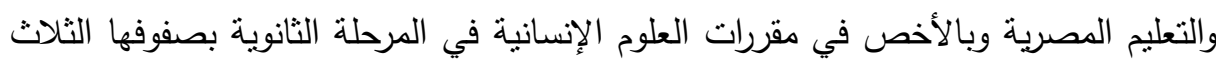

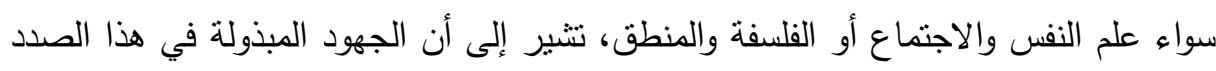

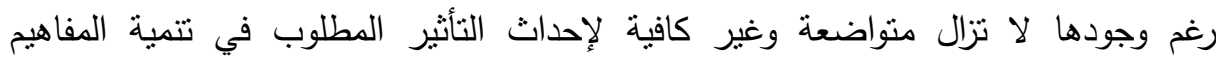

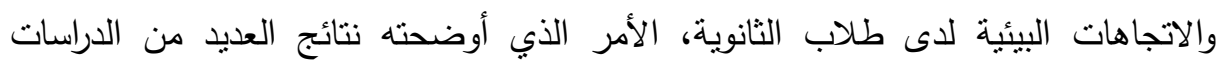

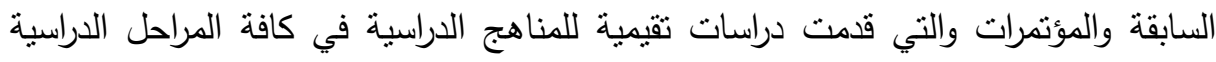

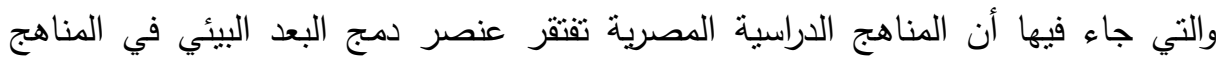
كدراسة (أيه عطية، (1 + إم ) والتي تؤكد إفتقار مناهج الثانوية العامة البعد البيئي، وبما أن للمدرسة دور في التحدي للأخطار البيئية عن طريق بث المعرفة والتوعية بهذه الأخطار بين

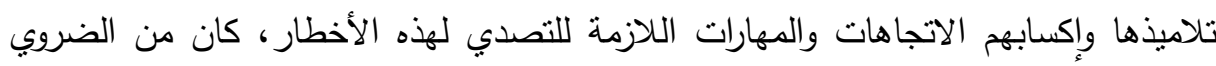

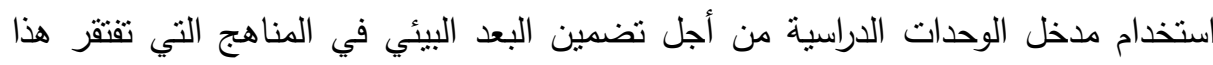

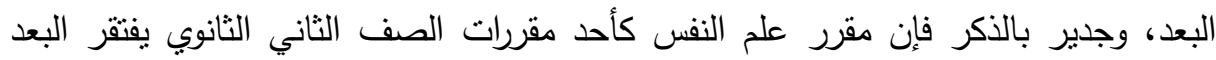
بيئي بين جوانبه؛ فكان من الضروري العمل علي تصميم وحدة مقترحة تتضمن البعد البيئي؛ من إجل تتمية سلوك إيجابي فعال نحو البيئة. يعد السلوك البيئي جزء من السلوك العام للفرد، والذي يكتسبه عن طريق التربية في

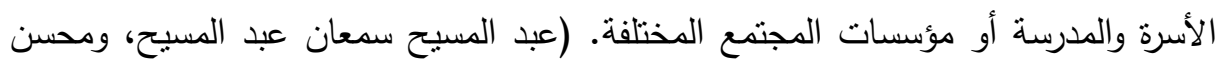

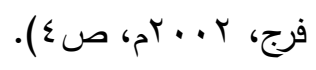

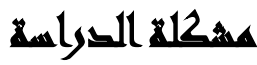

شعر الباحثون بمشكلة الدراسة من خلال عدد من روافد، تمثلت في مراجعة الدراسات السابقة، والإطلاع على العديد من الأطر النظرية، وبالأخص التي أجريت عن عن مدي تضدي تضدين المفاهيم والقضايا البيئية في المناهج الدراسية مثل دراسة (أسماء فؤاد الحجاوي، • ل • بام)،

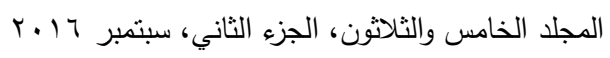




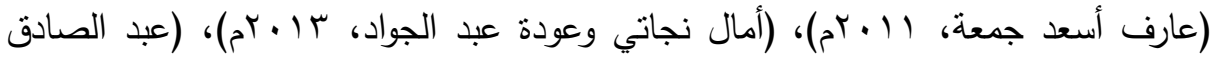
المبارك، 10 • بم). وتبين للباحثون وجود قصور و ندرة في المفاهيم والقضايا والاتجاهات البيئية بمقرر الصف الثاني الثانوي، من خلال قيامهم بتحليل محتوي مقرر علم النفس الجديد الصف الثاني الثانوي لعام 10 • بم-7 1 • بم، ودعم الإحساس بالمشكلة اجراء الباحثون دراسة إسنطلاعية تم التساؤل من خلالهاعلي مدي تضمين المقرر الحالي لعلم النفس لأي مفاهيم بيئية، أو أن المقرر الحالي ينمي الاتجاهات البيئية، وتكونت الدراسة الإستطلاعية من (YV) مفردة حول وحدات مقرر علم النفس الحالي للصف الثاني الثانوي وكانت بدائل الإجابة بـ (نعم الإنه

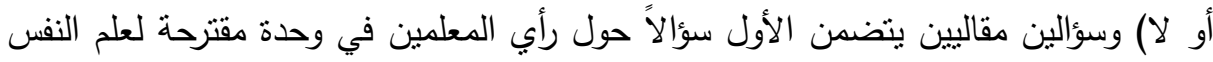
تتضمن بُعد بيئي والأخر يتضمن مقترحات المعلمين حول الوحدة المقترحة وقد نم تطبيق

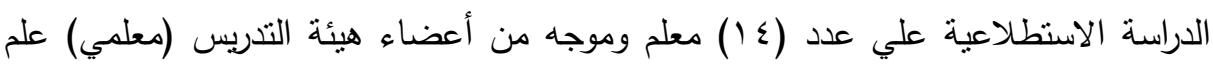

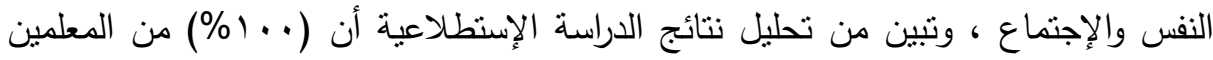
أثناروا بوجود قصور في مقرر علم النفس بالصف الثاني الثانوي - حيث ندرة المفاهيم

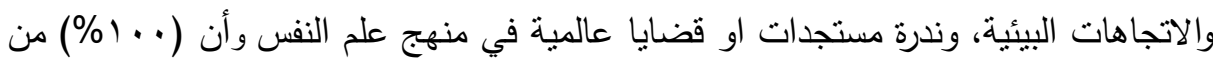
المعلمين أثناروا إلي ضرورة تطوير مقررعلم النفس الحالي من خلال تضمين بُعد بيئي في

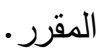

\section{أسئل التوراسما}

التساؤل الرئيسي للاراسة: "ما فعالية وحدة مقترحة بمقرر علم النفس قائمة علي (النظرية البنائية الاجتماعية) لفيجوتسكي في تنمية المفاهيم والاتجاهات البيئية لطلاب الصف الثاني الثانوي؟" الثاب وينبثق منه التساؤلات الآتية: الفي ا-ما القضايا والمفاهيم البيئية المرتبطة بمقرر علم النفس التي ينبغي توافرها لطلاب الصف

$$
\text { الثاني الثانوي؟ }
$$

r-مامدي تضمين هذه القضايا والمفاهيم بمقرر علم النفس لطلاب الصف الثاني الثنانوي؟

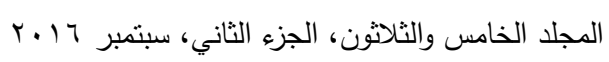


ץ-ما تصور وحدة مقترحة بمقرر علم النفس قائمة علي (النظرية البنائية الاجتماعية)

$$
\text { لفيجوتشكي؟ }
$$

ع-ما فعالية الوحدة المقترحة في تتمية المفاهيم البيئية لطلاب الصف الثاني الثانوي؟

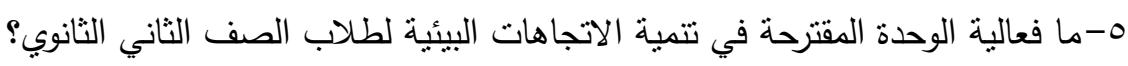

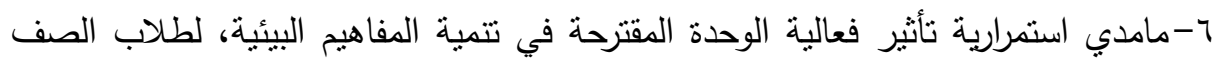

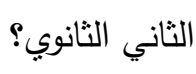

V-مامدي استمرارية تأثير فعالية الوحدة المقترحة في تتمية الاتجاهات البيئية لطلاب الصف

$$
\text { الثاني الثنانوي؟ }
$$

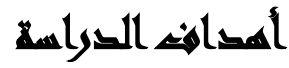

هدفت الدراسة الحالية إلي تتمية الدفاهيم والاتجاهات البيئية لدي طلاب الصف الثاني الثانوي، من خلال وحدة مقترحة بمقرر علم النفس.

\section{هورن الفواسمة}

ا. توجد فروق دالة إحصائياً بين درجات الطلاب في القياسين القبلي والبعدي للاختبار التحصيلي بمستوياته الثلاثة (التذكر - الفهر - التطبيق) لصالح التطبيق البعدي.

r. توجد فروق دالة إحصائياً بين درجات الطلاب في القياسين القبلي والبعدي لمقياس الاتجاهات البيئية لصالح التطبيق البعدي. r. لا نوجد فروق دالة إحصائياً بين درجات الطلاب في القياسين البعدي والتتبعي للاختبار التحصيلي بمسنوياته الثناثة (التذكر - الفهر - التطبيق).

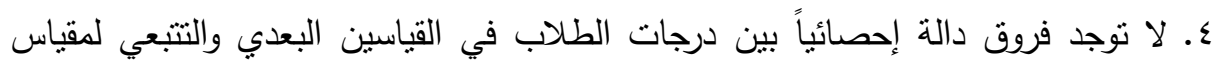

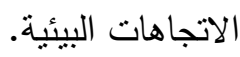




\section{مسوض الصراسلة}

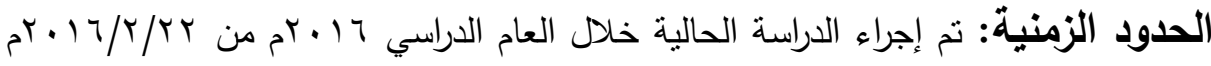
وحتى الما

الحدود البشريةة: نم نطبيق الوحدة المقترحة علي مجموعة من طلاب وطالبات الصف ملآل الثاني الثانوي، القسم الأدبي. الحدود المكانية: تم تطبيق الوحدة المقترحة في مدرسة بشتيل الثانوية المشتركة، التابعة لإدارة الوراق التعليمية، محافظة الجيزة.

\section{منهمج الترواسلة}

المنهج شبه التجريبي: يدرس فعالية المتغير المستقل (الوحدة المقترحة)، وتحديد ما

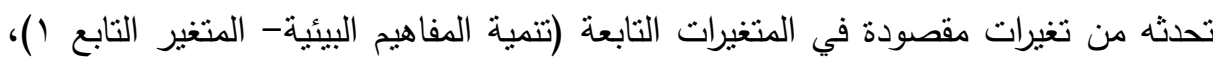
(تتمية الاتجاهات البيئية - المتغير التابع ب).

\section{أهمية الصوراسما}

• تساعد نتائج الدراسة مخططي المناهج الدراسية في وزارة التربية والتعليم المصرية، وذلك اعلك من خلال وضع اطار عام لكيفية إعداد وحدة دراسية تساهم في تتمية المفاهيم والاتجاهات البيئية من خلال مقرر علم النفس والاجنماع. • تعيد توجيه الباحثين البيئيين إلي أهمية النظرية البنائية الاجتماعية في التعلم وعملية التعليم.

\section{مخاهيه الصراسة}

الوحدة الاراسية: تتظيم خاص للمادة الدراسية وطريقة للتدريس تهيئ التلاميذ لمواقف

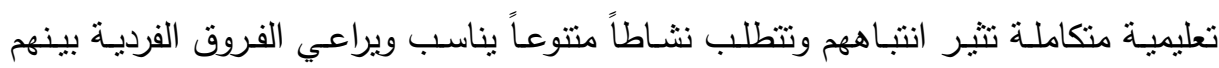


ويتطلب مرورهم بخبرات تربوية معينة وهذا يؤدي إلى فهم المعرفة واكتساب مهارات وعادات

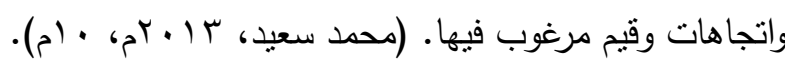

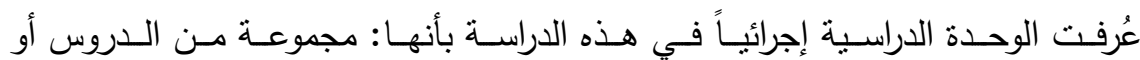
الموضوعات ذات الصلة ببعضها البعض، وتهدف إلي إكساب الطلاب مجموعة من الحقائق والمفاهيم والقيم والاتجاهات الإيجابية نحو البيئة وتربط مابين سلوك الإنسان وما يحدث في لي لئه

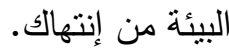
النظرية البنائية الاجتماعية لفيجونسكي: وكما عُرف بأنه: "أسلوب للندريس لإكساب طلاب المفاهيم المتضمنة في المادة المقررة، والنهوض بقدراتهم علي التفكير الابداعي بتفاعلهم الإجتماعي مع المعلم أو مع أقرانهم في الصف، بإستخدام اللغة والحوار والتفاوض والتفكير بصوت عالٍ في مجموعات صغيرة، يقوم المدرس فيها بتحديد المفاهيم، التي يُخطط

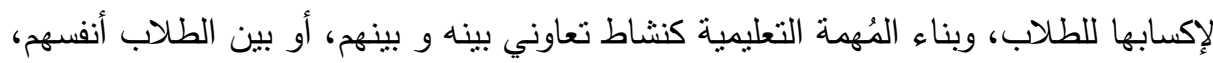

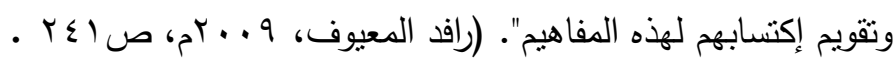
عُرفت النظرية البنائية الاجتماعية لفيجوتسكي إجرائياً في هذه الدراسة بأنها: "نموذج في التعليم والتعلم الاجتماعي، يقوم فيها المتعلم بدور فعال نشط إيجابي، من خلال عملية استخخال وإعادة بناء النشاط المعرفي الداخلي بالنشاط المعرفي الخارجي، وذللك عندما يشعُر لهُر الكُتعلم بالعجز أو الحاجة لمُساعدة من المحيطين؛ لتخطي مشكلة ما، من خلال عمليات التفاوض والمناقثة والحوار بين المعلم والطلاب، أو الطلاب وأقرانهم في مجموعات صغيرة، من أجل نتمية المفاهيم و الاتجاهات البيئية".

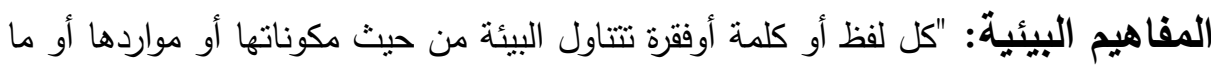

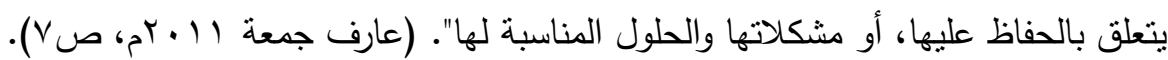

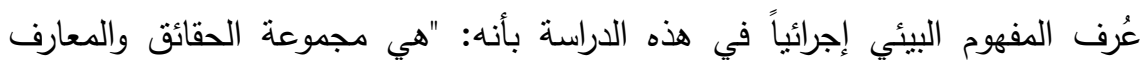
المنظمة عن البيئة في صورة لفظية، والتي تتعلق بماهية البيئة وكيفية الحفاظ عليها ومشكلاتها والحلول المناسبة للتعامل مع هذه المشكلة. 
الاتجاهات البيئية: "مجموعة استجابات الفرد تجاه موضوع جدلى معين من حيث القبول أو الرفض وتعتمد هذه الاستجابات على خبرات الفرد السابقة وتتميز بالثبات النسبى" (سعدية

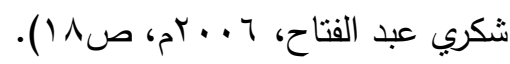

عُرفت الاتجاهات البيئية إجرائياً في هذه الدراسة بأنها: "تتظيم كلي يتضمن وجدان وأفكار ومعتقدات ونزعات الفرد تجاه قضايا بيئية، سواء بقبول قضايا تتعلق بسلاهة البيئة والحفاظ لهاه عليها، أو رفض كل مظاهر الإعنداء علي البيئة ومكوناتها، ويظهر الاتجاه من خلال درجاء الطلاب علي مقياس الاتجاهات". التربية البيئية: عُرفت بأنها: "فلسفة ونمط من التفكير هدفه الرئيسي توجيه العلاقات البشرية

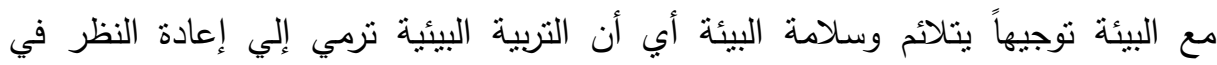

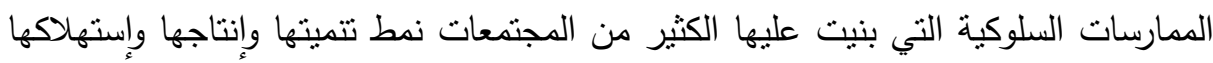
وتوضيح المفاهيم وإكساب الوعي والاتجاهات والقيم وإنماء المهارات لتقدير العلاقة بين

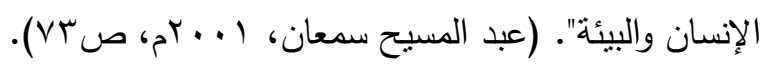

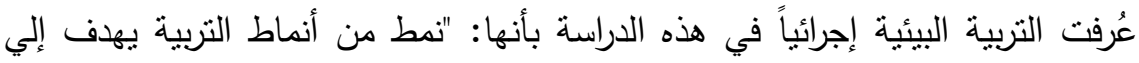

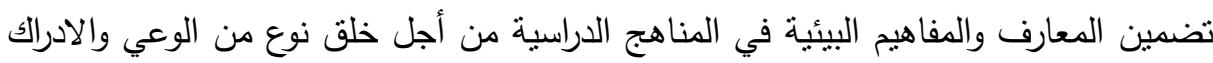

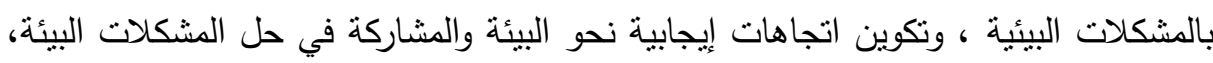
والحفاظ عليها بكل ما فيها من مكونات".

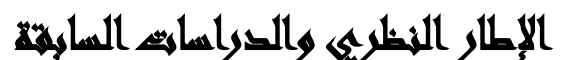

البنائية الاجتماعية في التعلم: تقترض النظرية البنائية الاجتماعية لفيجوتسكي أن المعلومات والخبرات والمعتقدات السابقة تقوم بدور محوري في عملية التعلم القادمة أو التالية، فالأفراد يتعلمون بناء المعني من خلال التفاعلات الاجتماعية. (حسن زيتون، وكمال زيتون،

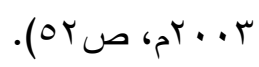

التعلم في ضوء البنائية الاجتماعية: يقوم التعلم في ضوء النظرية البنائية الإجتماعية علي منطلقات:

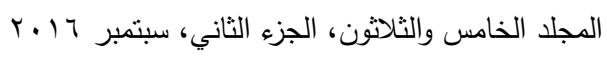


- المنطلق الأول للتعلم أنه تعلم بيولوجي: وطبقاً لفيجوتسكي التعلم يسبق النضج، حيث يري

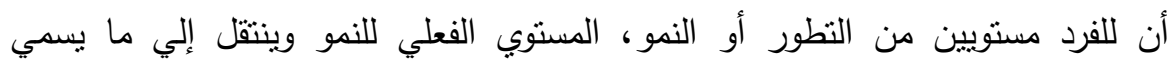

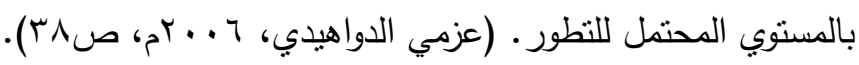
- المنطلق الثاني للتعلم بأنه نتعلم إجتماعي تاريخي: فالتعلم عملية مُشاركة إجتماعية ديناميكية، تتم في حوار بين المعلم، والمتعلم ، أو مع الأقران، أو أصحاب الخبرة، ويُركز

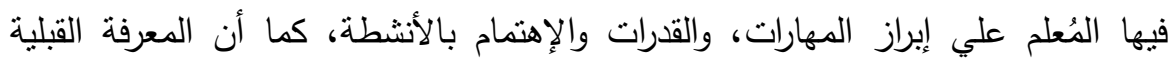

$$
\text { للمتعلم شرط أساسي لبناء التعلم ذي المعني. }
$$

- المنطلق الثالث للتعلم أنه يحدث في سياقات ذات معني: فالمُتعلم يتأثز بكل من السياق

$$
\text { الثقافي والإجتماعي. }
$$

- المنطلق الرابع للتعلم هي ما يكتسبه الفرد من خبرات: الخبرات (المُعانشة) تاريخية: وهي

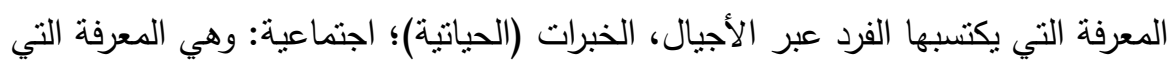

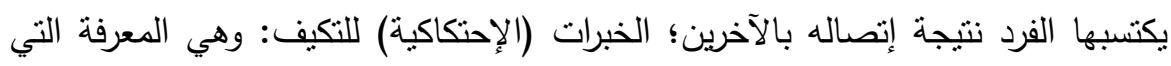

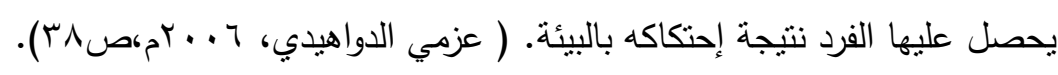

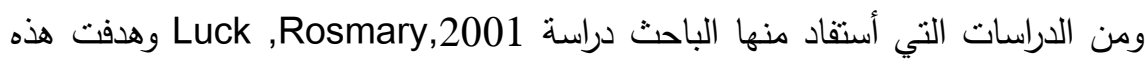

الدراسة إلى (تصميم برامج تربوية الكترونية للاطفال مستتدة إلي القضايا التفاعلية والتعاون حسب نظرية فيجوتسكي، وتهدف البرامج إلي تعلم الاطفال من سن 10-11 عاما معلومات

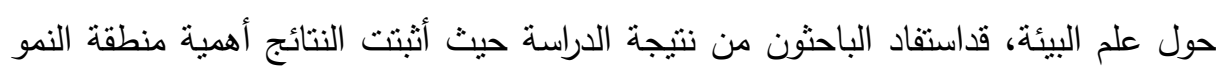

$$
\text { القريبة المركزية في تصميم البرامج التربوية. }
$$

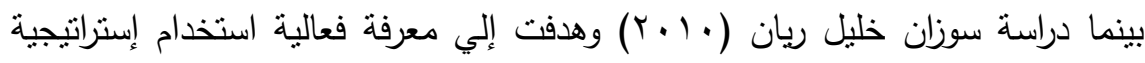
فيجوتسكي في تدريس الرياضيات وبقاء أثز التعلم لدي طالبات الصف الساد بغزة. اختلفت الدراسة الحالية عن دراسة سوزان خليل في التصميم التجريبي، كما استفاد الباحثون من نتائج الدراسة التي أثنارت إلي وجود فروق بين متوسطات درجات الطلاب في المجموعة التجريبية وبين متوسطات درجات الطلاب في المجموعة الضابطةالتي تعلمت بالطريقة الاعتادية. 
المفاهيم البيئية: بالرغم من الجهود المبذولة لتضمين المفاهيم البيئية في المناهج الدراسية، إلا

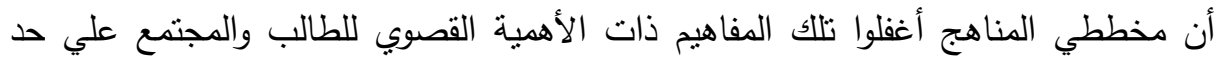
سواء؛ فنتج عن ذلك تدني الإحساس بالمسؤولية نحو البيئة من قبل مخرجات المراحل الدراسية ومن ثم فهناك العديد من المُهتمين في المجال التربوي والباحثين الذين قد رصدوا هذا القصور

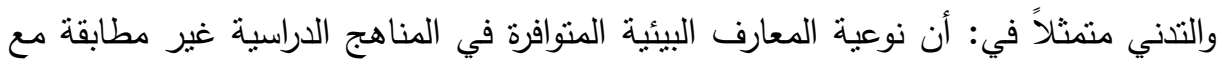

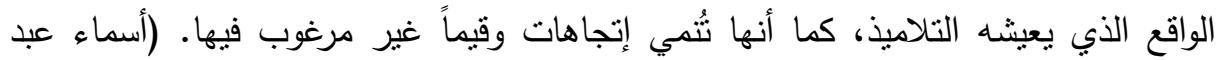

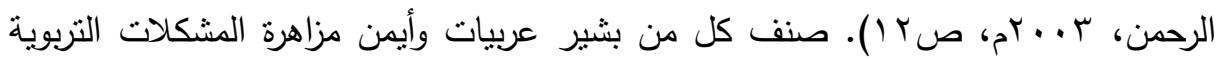

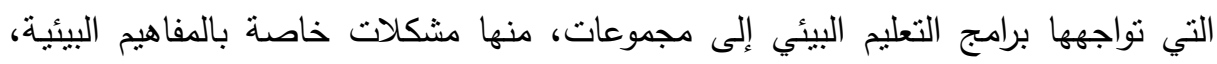
حيث نوافرت مفاهيم بيئية مغلوطة أدت إلى الفثل في إحداث الوعي اللازم عن الشيكلات البيئية الملحة؛ مما تضمين مفاهيم صحيحة في مناهج التعليم. (بثير عربيات، وأيمن مزاهرة،

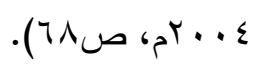

وقد استفاد الباحث من دراسة إيمان العباسي (9 . . ب) هدفت الدراسة إلى (دراسة فاعلية وحدتين مقترحة باستخدام المدخل البيئي وبعض الاستراتيجيات الحديثة لتتمية المفاهيم البيئة لطالبات الصف الأول المتوسط وأثره في اكتسابهن الاتجاهات البيئية في المملكة العربية السعودية، وأن كلاهما كان يستخم الاستراتيجيات الحديثة، وأن كلاهما قاما بتحليل المحتوي وبناء الوحدات الدراسية، كما استقاد الباحث من أدوات الدراسة في إعداد (الاختبار

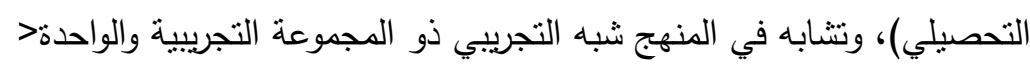

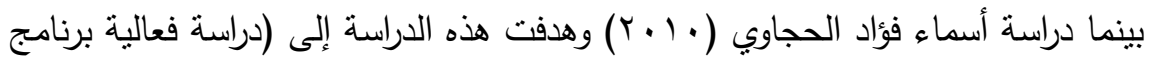

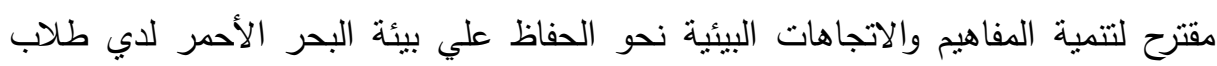
المرحلة الإعدادية بمحافظة جنوب سيناء، وقد استفاد الباحث من الإطار النظري للمفاهيم البيئية وفي إعداد أدوات الدراسة (الاختبار التحصيلي ومقياس الاتجاهات البيئية)، واستخدمت لئناه اسماء المنهج التجريبي ذو المجموعة الواحدة وتتفق الدراسة مع الدراسة الحالية.

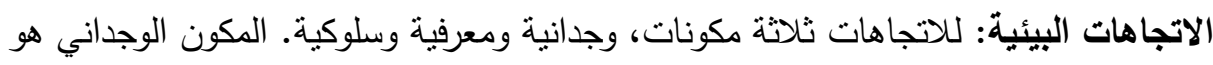

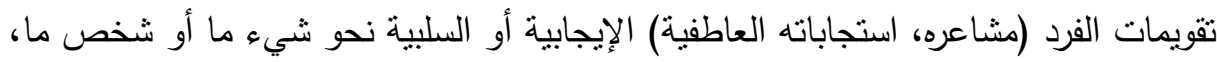
والمكون المعرفي هومعلومات الفرد ومعتقداته عن موضوع الاتجاه، أو معرفته بالوقائع حوله،

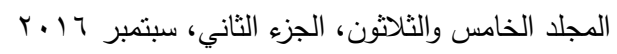


والمكون السلوكي هو السلوكيات التي يقوم بها الفرد وتتعلق بموضوع الاتجاه، فيشمل السلوك

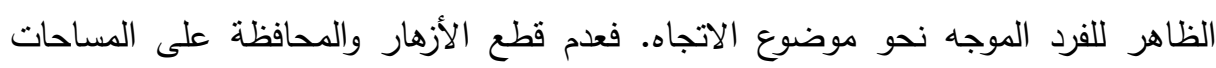
الخضراء والإبقاء على برية الأماكن الطبيعية الخلوية أمثلة للمكونة السلوكي للاتجاه نهوراه

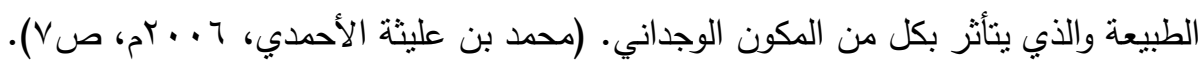

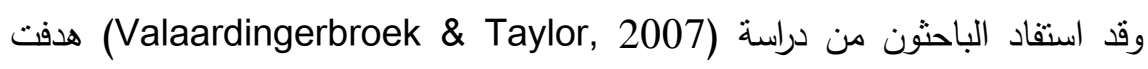
هذه الدراسة إلي (الكثف عن الثقافة البيئية والاتجاهات نحو البيئة لدى الطلبة المعلمين في

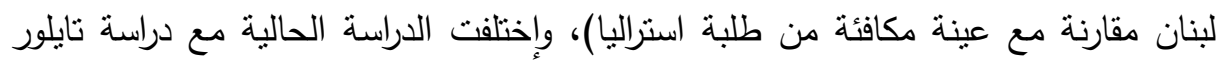

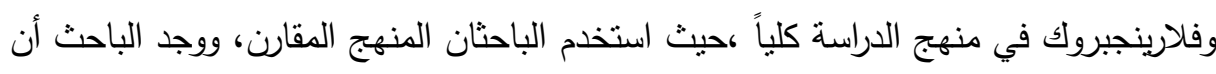

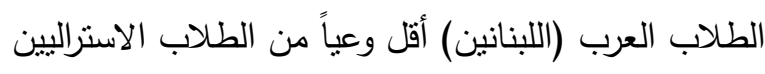

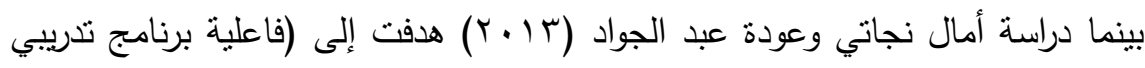

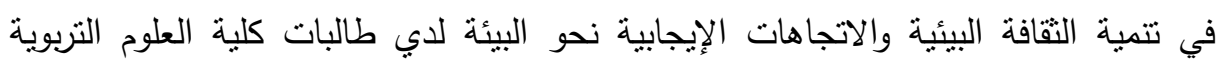

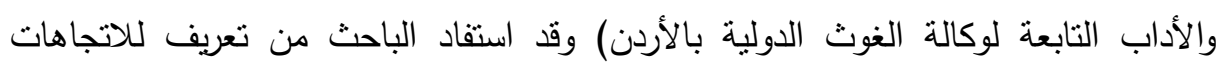

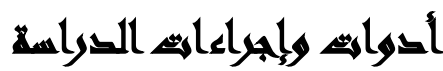

عينة الدراسة: تكونت العينة الاستطلاعية من (T) (I) طالب وطالبة، بينما تكونت العينة

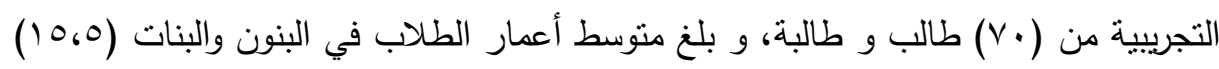
سنة تقريباً، وقد تم الحصول على العمر الزمني لكل طالب من واقع السجلات الرسمية في المدرسة. مجتمع الدراسة وعينته: تم اختيار عينة الدراسة التجريبية الواحدة بطريقة قصدية من طلاب مدرسة بشتيل الثانوية المشتركة. إعداد أدوات الدراسة: شملت أدوات الدراسة ما يلي: إعداد وتصميم الوحدة المقترحة، إعداد

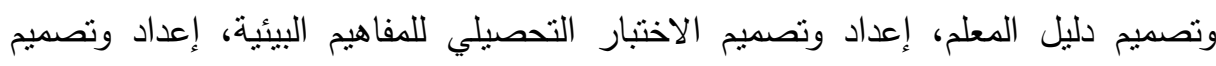
مقياس الاتجاهات البيئية. 
إعداد الوحدة المقترحة: قام الباحث بتصميم الوحدة الدراسية المقترحة من خلال منهج الوحدات الدراسية وفيما يلي خطوات ومراحل إعداد الوحدة المقترحة كما يلي: الفلسفة القائمة عليها الوحدة المقترحة: قد تبني الباحث الوحدات الدراسية القائمة علي المادة

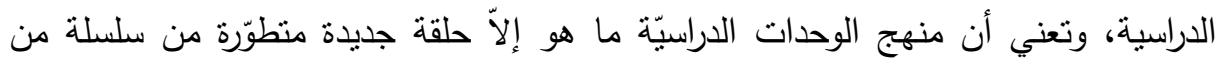

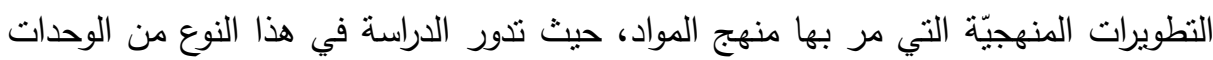
حول محور رئيسي (علم النفس البيئي) يثتقّ من المادّة الدراسيّة ذاتها (علم النفس)، ولكنّه فئه

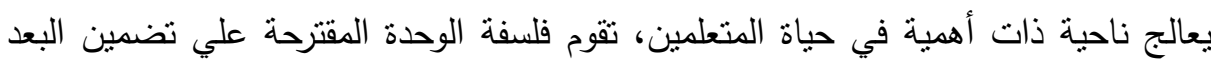

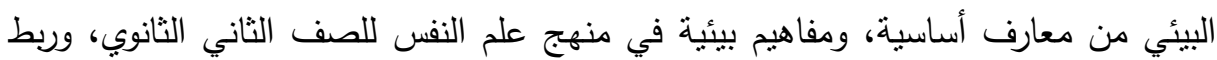
الوحدة بحاجات ومشكلات التلاميذ البيئية ومتطلبات الواقع الفعلي الذي يعيشونه. أهداف الوحدة المقترحة: لقد وضع الباحث عدة أهداف عامة للوحدة المقترحة كما يلي:( ) تتمية القدرة علي مواصلة التعليم والتعلم من خلال التعلم الاجتماعي. r بتمية الاتجاهات الايجابية لاي الطلاب من خلال مواقف ومعارف علم النفس البيئي. r) التعريف بأهم المفاهيم البيئية. ع) إبراز أهم السلوكيات الانسانية السلبية تجاه البيئة. 0) استخلاص أهم السلوكيات المرغوبة تجاه البيئة. محتوى الوحدة المقترحة: قام الباحث بتصميم الوحدة المقترحة بعنوان (علم النفس والبيئية) وتكونت الوحدة من ستة دروس (موضوعات) كما يلي: الموضوع الأول: نشأة علم النفس البيئي وتطوره وموضوعاته. الموضوع الثاني: تعريف علم

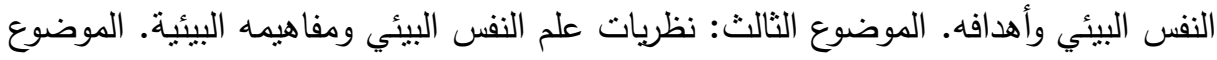
الرابع: السلوك الإنساني والبيئة. الموضوع الخامس: البيئة والصحة النفسية. الموضوع السادس: آليات التعامل مع البيئة. طريقة تدريس الوحدة المقترحة: نموذج التعلم البنائي الإجتماعي. 
الأنثطة التعليمية المصاحبة للوحدة المقترحة: قد استخدم الباحث المعلم العديد من الأنشطة كالأنشطة الجماعية (المشاركة- الحوار - المفاوضة) أثناء الحصة، أنشطة تتمية مهارات التفكير الجمعي (مشروعات بحثية- نقارير ما بعد الحصة)، أنشطة حياتية (حل المشكلات البيئية). تقويم الوحدة المقترحة: استخدم الباحثون كل أنواع وصور التقويم كالتقويم المبدئي، ففي بداية الحصة استخدم الباحث المعلم التقويم المبدئي لربط الدرس القديم بالدرس الجديد؛ والثقويم التكويني، ثم استخدم الثقويم التكويني أثناء الحصة بطرح اسئلة مستمرة؛ والثقويم النهائي، استخدم الباحث التقويم النهائي للتأكد من تحقيق الأهداف التي وضعها، فالتقويم عملية مستمرة ومتصلة وشاملة.

إجراءات ضبط الوحدة المقترحة: قام الباحث بضبط الوحدة المقترحة من ناحيتي التنظيم المنطقي والتنظيم السيكولوجي حيث الإنتقال من الجزئي للكلي ومن السهل للصعب، فاعنة الباحث بإعداد الوحدة المقترحة بمقرر علم النفس القائمة علي النظرية البنائية لفيجوتسكي. عرض الوحدة المقترحة علي بعض السادة المحكمين: قام الباحث بعرض الوحدة علي السادة المحكمين لإجراء التعديلات اللازمة وذلك للوصول إلي الصورة النهائية للوحدة

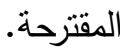
إعداد دليل المعلم للوحدة المقترحة: قام الباحث بإعداد دليل المعلم وراعي الباحث أن يتكون هذا الدليل من العناصر التالية: - التاليل 1- الأهداف العامة للوحدة المقترحة في مقرر علم النفس. r- خريطة المنهج للوحدة المقترحة في مقرر علم النفس. r- فلسفة الدليل والاستراتيجيات المستخدمة في تدريس الوحدة المقترحة. ع - نوجيهات للمعلم داخل الفصل. ه- الموضوعات الرئيسية وعدد الحصص اللازمة والخاصة بتدريس كل موضوع. צ-إعداد الدروس في كل الموضوعات.

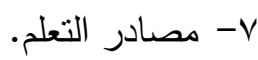


1- قائمة بالكتب والمراجع التي لجأ لها المعلم.

وبذلك تم الإجابة علي التساؤل الثالث وهو عن: ما تصور وحدة مقترحة في مقرر علم

النفس قائمة علي النظرية البنائية الاجتماعية لفيجوتسكي.

إعداد الإختبار التحصيلي للمفاهيم البيئية: تم إعداد اختبار المفاهيم البيئية بحيث يرتبط بالمحتوي العلمي للموضوعات الدراسية للوحدة المقترحة، وقد نم الرجوع إلي بعض إلم إلى الدراسات السابقة في إعداد خطوات اختبار الدفاهيم البيئية ومن هذه الدراسات: دراسة إيمان

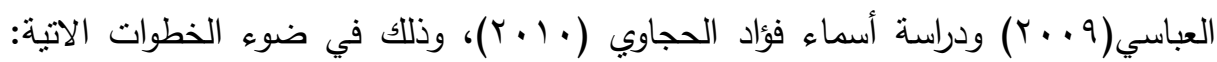
تحديد الهدف من الاختبار التحصبلي المفاهيم، وضع صياغة أسئلة الاختبار التحصيلي

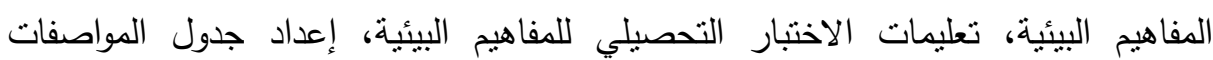

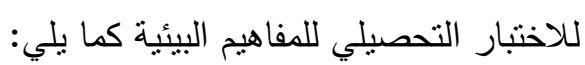
- حساب زمن اختبار المفاهيم: نم التسجيل التتابعي للزمن الذي أستغرقه أول طالب وأخر

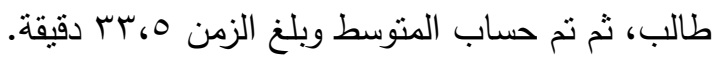
- تقدير درجات إختبار المفاهيم البيئية: نم تقدير الدرجات بحيث تمنئ تكون درجة واحدة للإجابة الصحيحة وقد أصبحت الدرجة الكلية . ج درجة وذلك في ضوء أراء الصحكمين ويتم التصحيح في ضوء نموذج إجابة الاختبار التحصيلي للمفاهيم البيئية.

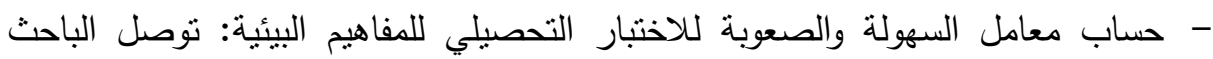
إحصائياً من حساب منوسط معامل السهولة بمنوسط وهو (7ء، •) وهو معامل سهولة

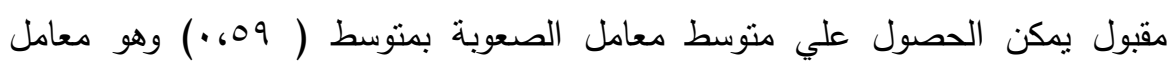
صعوبة مقبول.

- الخصائص السيكومنرية للاختبار التحصيلي للعينة الاستطلاعية:-

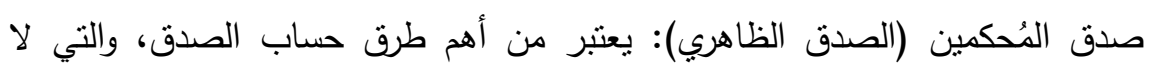

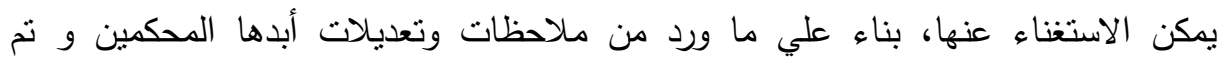

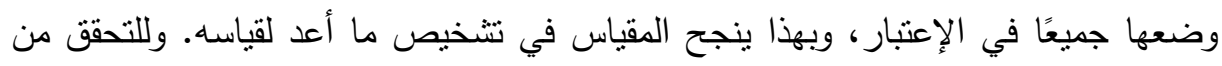


صدق الاختبار التحصيلي ( المفاهيم البيئية )، وتم عرض هذا الاختبار علي مجموعة من المحكمين. - حساب ثبات الاختبار التحصيلي للعينة الاسنطلاعية: قد ثم التحقق من ثبات المقياس من

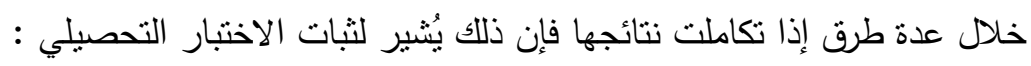
أ- معامل ألفا كرونباخ: هو متوسط مجموع معاملات ارتباط كل بند مع الدرجة الكلية

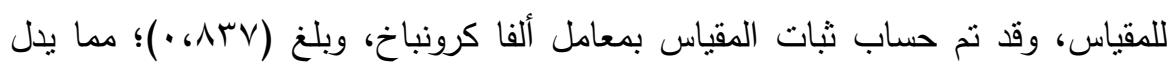
علي ثنات مقبول للاختبار • ب- طريقة التجزئة النصفية: حيث تعمل علي تجزئة الاختبار إلى نصفين متكافئين للحصول

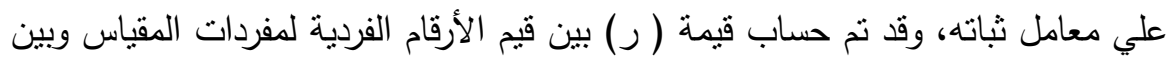

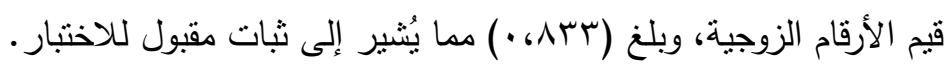

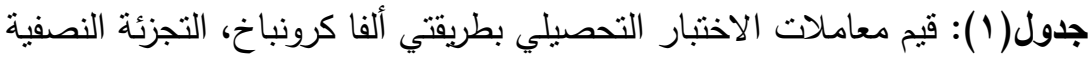

\begin{tabular}{|c|c|c|}
\hline التجزئة النصفيةً & آلفا كرونباخ & طرق الثبات \\
\hline 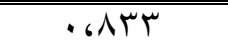 & . ‘АTV & نسبة التبات \\
\hline
\end{tabular}
تحديد الهذف من المقياس: يهدف المقياس إلى الكثف عن درجات الطلاب علي مقياس الاتجاهات البيئية. إعداد المقياس: أعد الباحثون المقياس من (•ج) مفردة، حيث بلغ عدد العبارات الموجبة

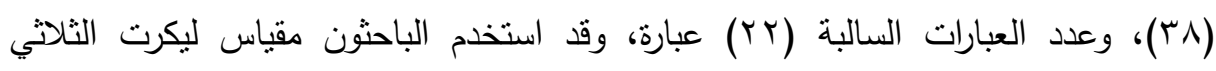

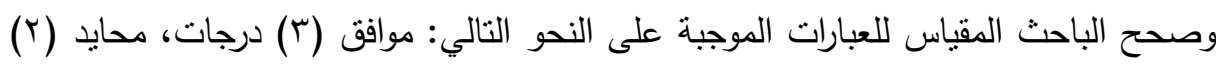
درجة، لا أوافق (1) درجة واحدة. وصححت العبارات السالبة: موافق (1) درجة واحدة، محايد

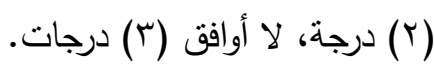
أبعاد المقياس : يتكون المقياس الحالي للبحث من ثنات أبعاد رئيسية.

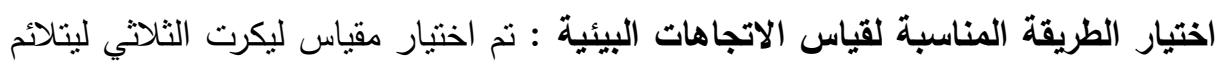
مع المرحلة ولسهولة حساب درجاته. 
تحديد زمن المقياس: الزمن الذي استغرقه أول طالب هو (Y0) دقيقة، والزمن الذي استغرقه اخر الطالب هو (مب) دقيقة، وأصبح الزمن الكلي لمقياس الاتجاه هو (•r) دقيقة. حساب درجات مقياس الاتجاه: نم حساب درجات المقياس بواقع • 1 ا درجة. الخصائص السيكومترية لمقياس الاتجاهات البيئية للعينة الاستطلاعية:

الصدق الظاهري (المُحكمين): يعتبر من أهم طرق حساب الصدق، والتي لا يمكن الاستغناء

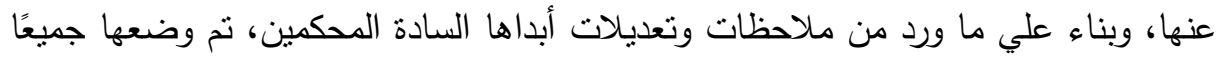
في الاعتبار، وبهذا ينجح المقياس في تتخيص ما أعد لقياسه. نم عرض مقياس الاتجاهات البيئية على مجموعة من المحكمين المختصين في كل من (معهر البحوث والدراسات البيئة بجامعة عين شمس - كلية البنات بجامعة عين شمس) لفحص مفردات المقياس والتأكد من من فين مناسبة العبارات للمحاور التي وضعت لقياسها، وأيضاً لإبداء آرائهم وإعطاء مقترحات لتعديل

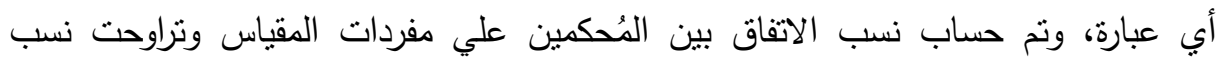

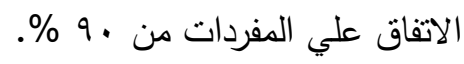

حساب ثبات مقياس الاتجاهات البيئية للعينة الاستطلاعية: قد نم التحقق من ثبات المقياس

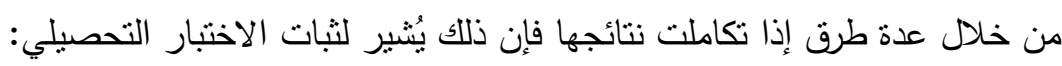
- معامل ألفا كرونباخ: هو منوسط مجموع معاملات ارتباط كل بند مع الدرجة الكلية

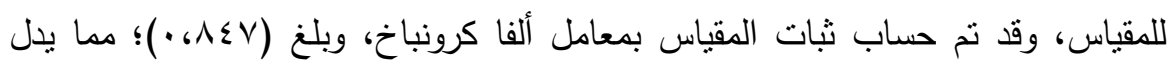
علي ثبات عال لمقياس الاتجاهات. - طريقة التجزئة النصفية: تُطبق علي مجموعة واحدة، حيث تعمل علي تجزئة الاختبار إلى نصفين متكافئين للحصول علي معامل ثباته، وقد تم حساب قيمة ( ر) بين قيم الأرقام

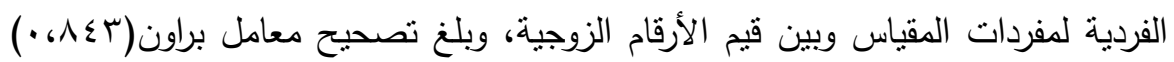
مما يُشير إلى ثبات عال لمقياس الاتجاهات البيئية. 
جدول(ץ): قيم معاملات الاختبار التحصيلي بطريقتي ألفا كرونباخ، التجزئة النصفية

\begin{tabular}{|c|c|c|}
\hline التجزئة النصفية & ألفا كرونباخ & طرق الثبات \\
\hline . ،八 $\leqslant r$ & $. ، \wedge \leqslant V$ & نسبة الثبات \\
\hline
\end{tabular}

مجموعة الاراسة: بلغ عدد الطلاب الذين قد طبقت عليهم الوحدة المقترحة (مب) طالباً، (T0) طالبة أي بمجموع ( ن=• V ) من طلاب الصف الثاني الثانوي القسم الادبي و قد تم

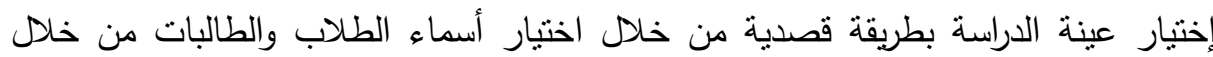
قوائم الفصول. تطبيق الاراسة: نم تطبيق الاختبار التحصيلي المفاهيم ومقياس الاتجاهات البيئية مجموعة

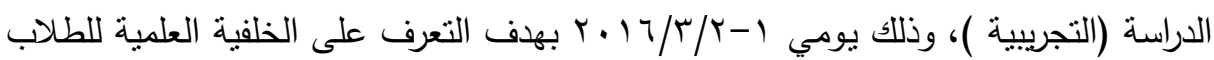
في المحتوى المعرفي لموضوعات الوحدة قبل إدخال المتغير المستقل، ومن ثم تم تصحيح

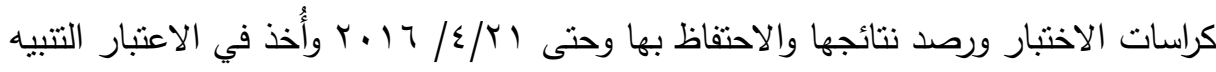
إلى كتابة الاسم، الفصل، المدرسة، شرح التعليمات للطلاب لضمان أداء الطلاب للاختبار بموضوعية، توجيه الطلاب إلى اختيار البديل علي يمين الاجابة، إخبار الطلاب بالوقت للإجابة على الأسئلة هو (ro) دقيقة فقط، التنبيه على جميع الطلاب بقراءة تعليمات الاختبار

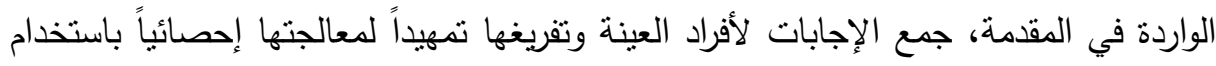
الحاسب الآلي ببرنامج (SPSS).

الأسلوب الإحصائي المستخدم: استخدم الباحث الأساليب الإحصائية التالية : - المتوسط الحسابي والإنحراف المعياري. - معامل الإرتباط (بيرسون وبراون).

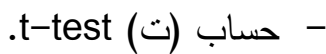
- معامل ثبات ألفا كرونباخ والتجزئة النصفية. - - مدق المجموعات المتضادة. - مربع إيتا، مربع أوميجا، حساب قيمة (d). 


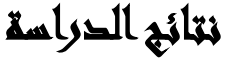

اختبار صحة الفرض الأول: للنحقق من صحة الفرض الأول من فروض الدراسة والذى

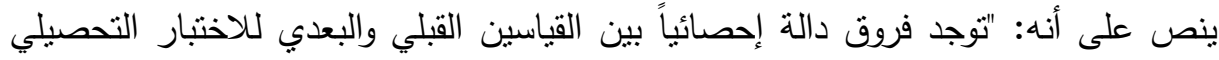

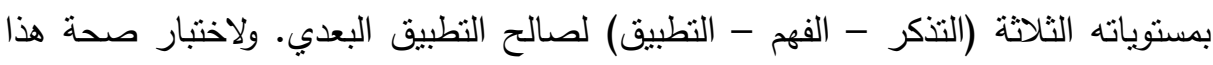

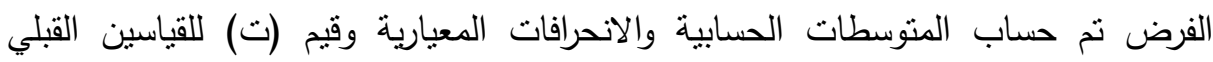

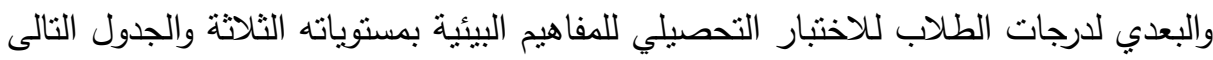
يوضح ذلك. جدول(َ): يوضح نتيجة اختبار (ت) للمقارنة بين درجات الطلاب في القياسين القبلي

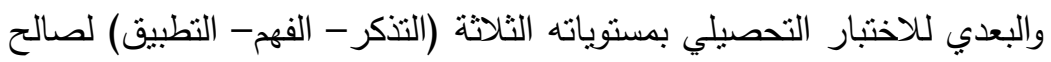

$$
\text { النطبيق البعدي. حيث (ن = • ( ) }
$$

\begin{tabular}{|c|c|c|c|c|c|}
\hline الا مستوي لالة عند & قيمة المحسوبة & الانحراف & المستوسطي & الاسئلة & مستويات الاختبار التحصيلي \\
\hline \multirow{2}{*}{ 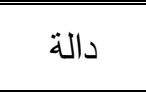 } & \multirow{2}{*}{ r $6.8 \wedge$} & $r_{6} \leqslant 9 \leqslant V$ & $1162 \ldots$ & $r$ & التذكر في الاختبار التحصيلي القبلي \\
\hline & & $\Gamma_{6} \wedge \leq \Psi \leq \varepsilon$ & $Y V_{6} \leq \varepsilon Y$ & $r$ & التذكر في الاختبارالتحصيلي البعدي \\
\hline \multirow{2}{*}{ 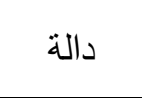 } & \multirow{2}{*}{$r \leq 6.1$} & E.)VTYV & $\left.V_{6} \leq V\right) \leq$ & YI & الفهم في الاختبارالتحصيلي القبلي \\
\hline & & r.V9 509 & $111690 \mathrm{~V}$ & YI & الفهم في الاختبارالتحصيلي البعدي \\
\hline \multirow{2}{*}{ 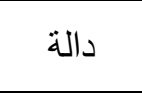 } & \multirow{2}{*}{1.60 .1} & r.TYTO. & r.7VIE & 9 & التطبيق الاختبارالتحصيلي القبلي \\
\hline & & Y.) YV9. & $7.50 \mathrm{VI}$ & 9 & التطبيق الاختبارالتحصيلي البعدي \\
\hline \multirow{2}{*}{ 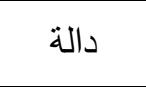 } & \multirow{2}{*}{$r V_{6} \leqslant V^{\prime}$} & $V_{6} 7 Y \leq \varepsilon$ & Y1. 710 & 7. & الاختبار التحصيلي القبلي ككل \\
\hline & & $0 . \leqslant 0 V V$ & $O Y_{6} \wedge \leqslant Y$ & 7 . & الاختبار التحصيلي البعدي ككل \\
\hline
\end{tabular}

يلاحظ من جدول (r) وجود فروق دالة إحصائياً فى جميع مستويات الاختبار التحصيلي

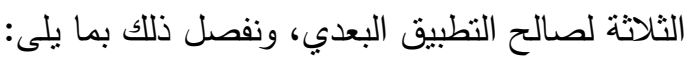
الاختبار التحصيلي القبلي والبعدي ككل: قيمة (ت) المحسوبة للاختبار التحصيلي تساوى (rV، (YrV)

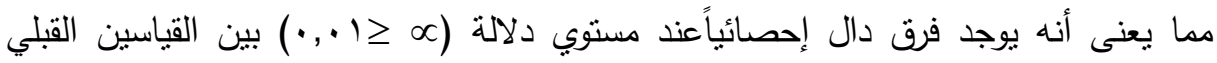
والبعدي للاختبار التحصيلي ككل. 
حساب حجم التأثير للوحدة المقترحة: من خلال تحويل "T"إلي " خ " و تحويل“T” مباشرة

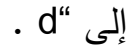

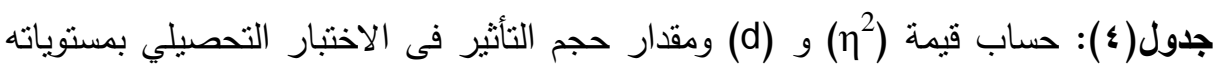
الثناث (التذكر - الفهر- النطبيق).

\begin{tabular}{|c|c|c|c|c|c|c|}
\hline التأثخر & $\eta^{2}$ & قيم d & المَّمسوية (ت) & مستويات الاختبار & التابعير & المستقليز \\
\hline كبير & س & $V_{6} \varepsilon \wedge Y$ & r1,. & التذكر في الاختبارالتحصيلي & \multirow{4}{*}{ البيئة الهيم } & \multirow{4}{*}{ 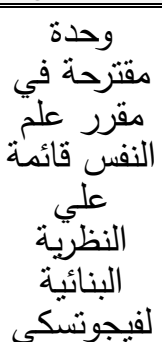 } \\
\hline كبير & • ‘А9 & $0_{\text {C }} \wedge \vee$. & $r \varepsilon_{6} \ldots \lambda$ & الفهم في الاختبارالتحصيم البحديلي & & \\
\hline كبير & .6710 & T.OYA & 1.60 .1 & النطبيق الاختبارالتحصيلي & & \\
\hline كبير & $.690 \mathrm{r}$ & $96.1 \leq$ & $r V_{6} \leqslant \mu_{\Lambda}$ & الاختبار التحصيلي آلبعدي & & \\
\hline
\end{tabular}

نجد أن حجم التأثير كبير فى كل مستوي التذكروالفهم والتطبيق، وذلك نتيجة تدريس الوحدة المقترحة من خلا نموذج التعلم البنائي الاجتماعي، مما أدى إلى ارتفاع تحصيل طلاب وطالبات الصف الثانى الثانوى للمعارف والمفاهيم البيئية. حساب قوة تأثير الوحدة المقترحة القائمة علي النظرية البنائية الاجتماعية لفيجوتسكي فى لئه

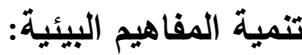
قام الباحث بتحديد قوة تأثثرها عن طريق حساب قيمة مربع أوميجا (ف́) وكانت النتائج كما فى الجدول التالي. جدول(ه): يوضح قيم مربع أوميجا (ف́) لبيان قوة تأثير الوحدة المقترحة القائمة علي النظرية

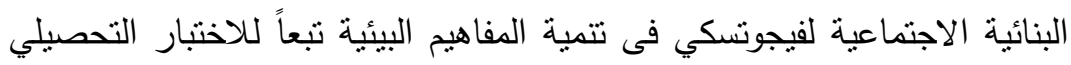

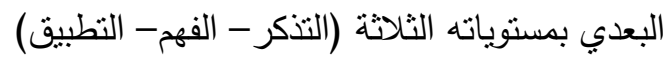

\begin{tabular}{|c|c|c|c|c|}
\hline قَوة التاتُّر & قيّم (ف́) & قيم (ت ) & مستويات الاختبار التحصيلى البعدي & P \\
\hline كبير جدا & •, qrr & TI..VA & التذكر في الاختبارالتحصيلي للمفاهيم البعدي & 1 \\
\hline كبير جدا & . 6199 & $r \varepsilon_{6} \ldots \lambda$ & الفهم في الاختبارالتحصيلي للمفاهيم البعدي & r \\
\hline كبير جدا & $\cdot, 7.9$ & 1.60 .1 & التطبيق الاختبارالتحصيلي للمفاهيم البعدي & r \\
\hline كبير جدا & $.690 Y$ & $r V_{6} \varepsilon r \Lambda$ & الاختبار التحصيلي للمفاهيم ككل & $\varepsilon$ \\
\hline
\end{tabular}


يتضح من جدول (0) قوة تأثنر الوحدة المقترحة القائمة علي النظرية البنائية الاجتماعية لفيجوتسكي فى تتمية المفاهيم البيئية تبعاً للاختبار التحصيلي البعدي بمستوياته الثلاثة (التذكر - الفهم- النطبيق)، وهذا مؤشر يؤكد أن وجود الفروق يعود إلى أسباب من أهمها قوة تأثير المعالجة التجريبية.

وبذلك يُرفض الفرض الصفرى ويقبل البديل، الذى ينص على أنه: "توجد فروق دالة

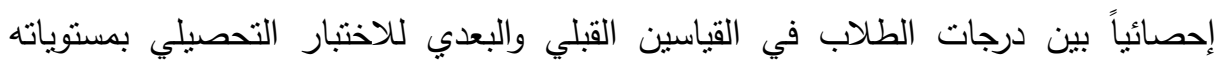
الثلاثة (التذكر - الفهم- التطبيق) لصالح التطبيق البعدي". وبذلك يتم الإجابة علي التساؤل الرابع من تساؤلات الدراسة والذى ينص على: "ما فعالية الوحدة المقترحة تتمية المفاهيم

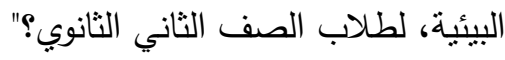

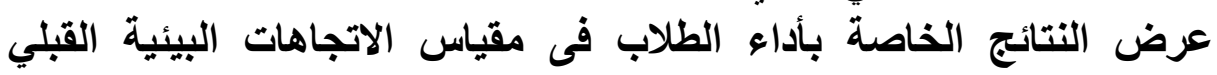
والبعدي وتفسير ها: اختبار صحة الفرض الثانى: للتحقق من صحة الفرض الثانى من فروض الدراسة والذى ينص على أنه: "توجد فروق دالة إحصائياً بين القياسين القبلي والبعدي لمقياس الاتجاهات البيئية لصالح النطبيق البعدي". ولاختبار صحة هذا الفرض تم حساب المتوسطات الحسابية والانحرافات المعيارية وقيم (ت) للقياسين القبلي والبعدي لدرجات الطلاب لدقياس الاتجاهات البيئية، والجدول التالى يوضح ذلك. 
مجلة العلوم البيئية

معهد الدراسات والبحوث البيئية - جامعة عين شمس لهن

جدول(؟): يوضح نتيجة اختبار (ت) للمقارنة بين المقياس القبلى والبعدى فى مقياس

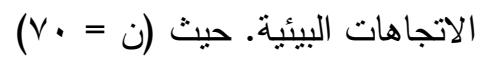

\begin{tabular}{|c|c|c|c|c|c|}
\hline 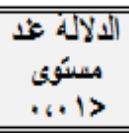 & المَّمِ (ت) & الإلمجرازث & الحصنابى المَّط & \multicolumn{2}{|c|}{ أبعاد الاججاهات البيشية } \\
\hline \multirow[t]{2}{*}{ Jد } & \multirow[t]{2}{*}{11,678} & 1 & 世r,9०V & مقياس الآجاهات البيئبة القبَلى & \multirow{2}{*}{ 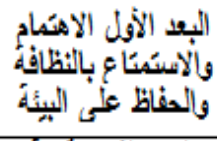 } \\
\hline & & Tr, KAO & $01,0 \leqslant 4$ & 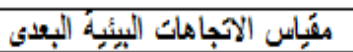 & \\
\hline \multirow{2}{*}{ د } & \multirow[t]{2}{*}{$1+4,+1$} & 1.79\% & ك & مقيّاس الآجاهات البيثِة القبّلى & \multirow{2}{*}{ 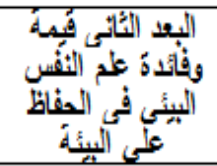 } \\
\hline & & 11678 & orsovi & مقِياس الآجاهات البيئِة البعاث & \\
\hline \multirow{2}{*}{ נد } & \multirow{2}{*}{116194} & $9,01$. & Hl, & 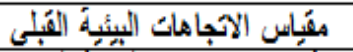 & \multirow{2}{*}{ 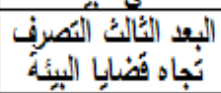 } \\
\hline & & $11,9 \% \mathrm{H}$ & $0.6 \% 10$ & 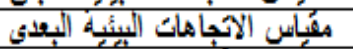 & \\
\hline \multirow[t]{2}{*}{ دل } & \multirow[t]{2}{*}{ rigiv } & $r 1,0497$ & 996,84 & \multirow{2}{*}{\multicolumn{2}{|c|}{ 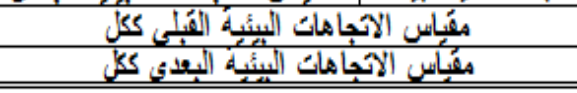 }} \\
\hline & & $10,7 \% 4$ & 1006010 & & \\
\hline
\end{tabular}

يلاحظ من الجدول (†) وجود فرق دال إحصائياً بين الدقياس القبلى والبعدى فى مقياس

الاتجاهات البيئية، ونفصل ذللك بما يلى:

مقياس الاتجاهات البيئية القبلي والبعدي ككل: كانت قيمة (ت) المحسوبة للمقياس تساوى

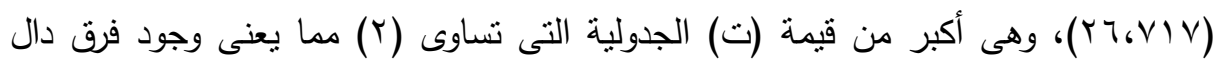

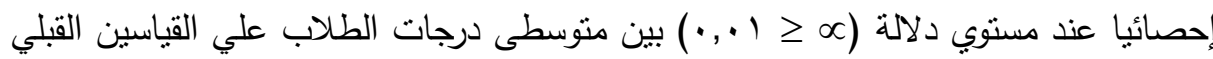
والبعدي لمقياس الاتجاهات البيئية لصالح التطبيق البعدي. حساب حجم التأثير : لحساب حجم تأثير الوحدة المقترحة القائمة (كمتغير مستقل) على (تتمية لانية الاتجاهات البيئية) (كمتغير تابع r) تم إيجاد مربع إيتا ( كما هو مبين بالجدول التالى. الن. 
جدول(V): حساب قيمة (谓) وقيمة (d) المقابلة ومقدار حجم التأثير الوحدة المقترحة القائمة علي النظرية البنائية الاجتماعية لفيجوتسكي فى تتمية الاتجاهات البيئية لمقياس

\begin{tabular}{|c|c|c|c|c|c|c|}
\hline & & & & \multicolumn{3}{|c|}{ الاتجاهات البعدي } \\
\hline التأثبر & مريع ايتا & قيم d & قالقيم (تية ) & أبعاد مقياس الاتجاهات & التابعنير & المتغير المستقل \\
\hline كبير & . . & 17.74. & $11,64 \varepsilon$ & واللاستمتاع بالنظافئة الاهتمام & \multirow{4}{*}{ الاتجاهات } & \multirow{4}{*}{ فل وحلي مقرة مقترحة } \\
\hline كبير & $\cdot, \times 14$ & $r \cdot . q \vee q$ & $\mid r \cdot r \cdot 1$ & البع النفس البيائي فئئي & & \\
\hline كبير & צ & $10, . \times 9$ & 11,194 & البعد الثالث التصرف & & \\
\hline كبير & .6911 & ו ו ו & YT.VIV & مقياس الاتجاهات & & \\
\hline
\end{tabular}

وبالنظر إلى الجدول السابق يتضح أن حجم تأثثر الوحدة المقترحة القائمة علي النظرية

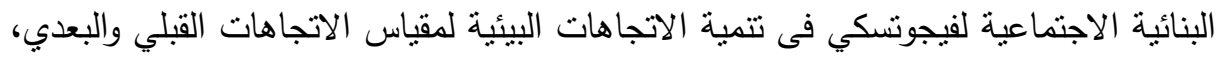

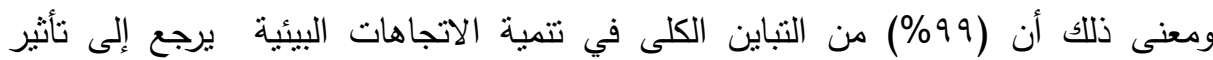

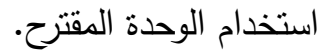

فعالية الوحدة المقترحة: للتأكد من فعالية الوحدة المقترحة القائمة علي النظرية البنائية الاجتماعية لفيجونسكي فى تتمية الاتجاهات البيئية، قام الباحث بتحديد قوة نأثيرها عن طريق

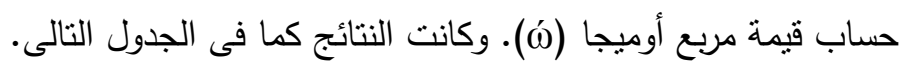

جدول(^): حساب قيم مربع أوميجا (ف́) لبيان قوة تأثثر الوحدة المقترحة القائمة علي النظرية

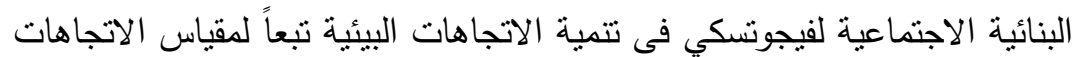

\begin{tabular}{|c|c|c|c|}
\hline قوقة التأثير & قَيم (ف́) & قيم (ت) & آبعاد مقياس الاتجاهات البيئية. \\
\hline كبير جدا & & $11,67 \varepsilon$ & البعد الأول الاهتمام والاستمتاع بالنظافة والحفاظ \\
\hline كبير جدا & . & $1 \pi_{G} T_{.}$ & البعد الثانى قيمة وفائدة علم النفس البئة البيئي فى \\
\hline كبير جدا & .6749 & 116194 & البعد الثالث التصرف تجاه قضايا البيئة \\
\hline كبير جدا & $\cdot, 99$. & N0,AM & مقياس الاتجاهات البيئية البعدي ككل \\
\hline
\end{tabular}


يتضح من جدول (^) حجم تأثثير الوحدة المقترحة القائمة علي النظرية البنائية الاجتماعية لفيجوتسكي فى تتمية الاتجاهات البيئية ، وهذا مؤشر يؤكد أن وجود الفروق يعود لئرد

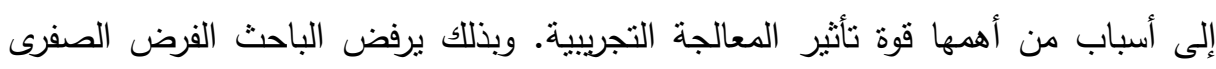

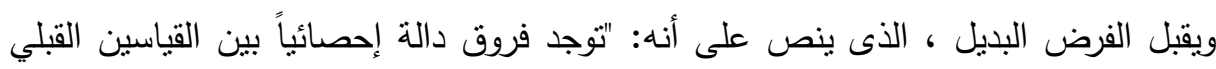
والبعدي لمقياس الاتجاهات البيئية لصالح التطبيق البعدي". وبذلك ينم الإجابة علي التسأؤل الخامس والذي ينص على الانه: "ما فعالية الوحدة المقترحة

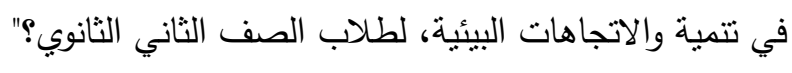

عرض النتائج الخاصة بأداءالطلاب فى الاختبار التحصيلي البعدي والتتبعي بمستوياته الثثلاثة وتفسيرها: اختبار صحة الفرض الثالث: للتحقق من صحة الفرض الثالث من فروض الدراسة والذى ينص على أنه: "لا توجد فروق دالة إحصائياً بين القياسين البعدي والتتبعي للاختبار

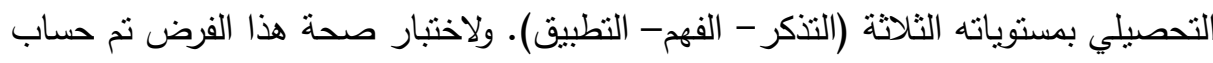
المتوسطات الحسابية والانحرافات المعيارية وقيم (ت) للقياسين البعدي والتتبعي لدرجات

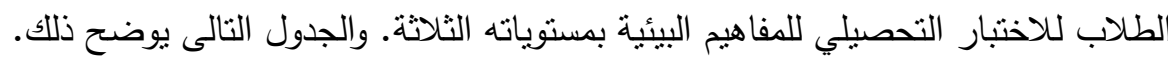


جدول(9): نتيجة اختبار (ت) للمقارنة بين القياسين البعدي والتتبعي للاختبار التحصيلي بمستوياته الثلاثة (التذكر - الفهم- النطبيق). حيث (ن = • V)

\begin{tabular}{|c|c|c|c|c|c|}
\hline الالالة ال.وي عند & قالمسوية (ت) & المعياري & الحسابي & الاسئلة & مستويات الاختبار التحصيلي \\
\hline \multirow{2}{*}{ غير دال } & \multirow{2}{*}{$r_{6} \ldots$} & $r, \wedge \leqslant r \leqslant \leqslant$ & $r V_{0} \leqslant \leqslant r$ & r. & التذكر في الاختبار التحصيلي \\
\hline & & r.qTIVE & r4.9९A & r. & التذكر في الاختبارالتحصيلي \\
\hline \multirow{2}{*}{ 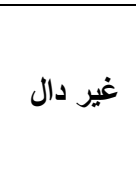 } & \multirow{2}{*}{$1, \ldots$} & r.VQ & $11.90 \mathrm{~V}$ & ri & الفهم في الاختبارالتحصيلي \\
\hline & & TGTITT & $1 \wedge, \vee \wedge 0$ & r & الفهم في الاختبارالتحصيلي \\
\hline \multirow{2}{*}{ غير دال } & \multirow{2}{*}{1,190} & rolrva. & $7 ، \leqslant 0 V$ & 9 & التطبيق الاختبارالتحصيلي البعدي \\
\hline & & $r, . I T \leqslant \leqslant$ & $7.7 \vee 1 \leqslant$ & 9 & التطبيق الاختبارالتحصيلى التتبعى \\
\hline \multirow{2}{*}{ غير دال } & \multirow{2}{*}{. . OVY } & 0 0. ००VV & $\Delta r_{6} \wedge \leqslant Y$ & 7. & الاختبار التحصيلي البعدي ككل \\
\hline & & $7,1 \leqslant V Y$ & Or.TVI & 7. & الاختبار التحصيلي التتبعي ككل \\
\hline
\end{tabular}

يلاحظ من جدول (9) عدم وجود فرق دال إحصائياً فى جميع مستويات التحصيل البعدي والتتبعي، ونفصل ذلك بما يلى: لئى

الاختبار التحصيل البعدي والتتبعي ككل: كانت قيمة (ت) المحسوبة للاختبار التحصيلي ككل

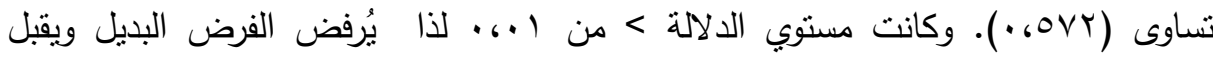
الفرض الصفري من فروض الدراسة والذى ينص على أنه: "لا نوجد فروق دالة إحصائياً بين

القياسين البعدي والتتبعي للاختبار التحصيلي بمستوياته الثناثة (التنكر - الفهم- النطبيق).

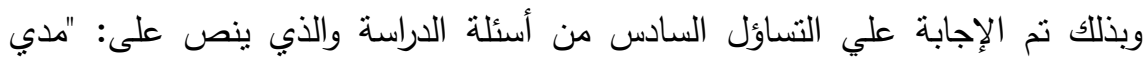
استمرارية تأثير فعالية الوحدة المقترحة في تتمية المفاهيم البيئية لطلاب الصف الثاني الثانوي؟ عرض النتائج الخاصة بأداء الطلاب فى مقياس الاتجاهات البيئة البعدي والتتبعي وتفسيرها: اختبار صحة الفرض الرابع: للتحقق من صحة الفرض الرابع من فروض الدراسة والذى ينص

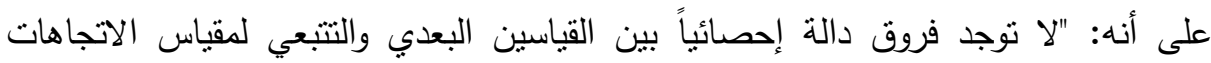

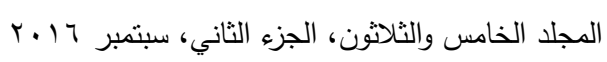


البيئية. ولاختبار صحة هذا الفرض نم حساب المتوسطات الحسابية والاتحرافات المعيارية وقيم (ت) للقياسين البعدي والتتبعي لمقياس الاتجاهات البيئية. الجدول النالى يوضح ذلك. جدول(• (1): نتيجة اختبار (ت) للمقارنة بين القياسين البعدي والتتبعي لمقياس الاتجاهات

البيئية

\begin{tabular}{|c|c|c|c|c|c|}
\hline الالالة عستوي & 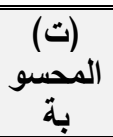 & الإنحراف & المستوسطي & \multicolumn{2}{|c|}{ أبعاد مقياس الاتجاهات البيئية } \\
\hline \multirow[b]{2}{*}{ غير دال } & \multirow[b]{2}{*}{. $6 \wedge 0$} & I r.r人q & $01,0 \leqslant Y$ & مقياس الاتجاهات البيئية & \multirow{2}{*}{ 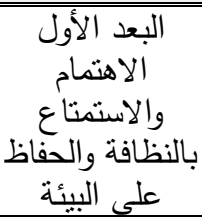 } \\
\hline & & I r.V.r & $016 \leqslant 1 \leqslant$ & مقياس الاتجاهات & \\
\hline \multirow{2}{*}{ 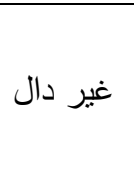 } & \multirow{2}{*}{ TGYTY } & $116 \vee 7 \varepsilon$ & or.ovi & مقياس الاتجاهات البيئية & \multirow{2}{*}{ 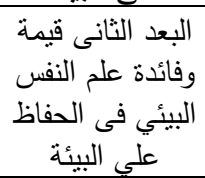 } \\
\hline & & $\left|r_{6}\right| \leq r$ & $0 r_{6}, T \wedge 0$ & مقياس الاتجاهات البيئية & \\
\hline \multirow{2}{*}{ غير دال } & \multirow{2}{*}{ r.TVV } & 11.941 & 0.6 Y 10 & مقياس الاتجاهات البيئية & \multirow{2}{*}{ التصرف البعد الثالثاه البئئة } \\
\hline & & $1 r_{6} .00$ & $\{9, r \vee \downarrow$ & مقياس الاتجاهات البيئيةالتتبعىى & \\
\hline \multirow{2}{*}{ 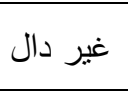 } & \multirow{2}{*}{$0.9 \vee 0$} & $1067 \leqslant Y$ & 100601 & \multirow{2}{*}{\multicolumn{2}{|c|}{ مقياس الاتجاهات البيئية البعدي ككل }} \\
\hline & & 106170 & $10 \mathrm{r}_{6} 0 \mathrm{~V}$ & & \\
\hline
\end{tabular}

يلاحظ من جدول (• (1) عدم وجود فرق دال إحصائياً فى القياسين البعدي والتتبعي لمقياس الاتجاهات البيئية بأبعاده الثلاثة. ونفصل ذلك بما يلى: مقياس الاتجاهات البيئية البعدي والتتبعي ككل: كانت قيمة (ت) المحسوبة للمقياس تساوى

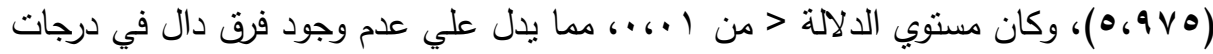
الطلاب في القياسين البعدي والتتبعي لمقياس الاتجاهات البيئية. وبذلك يُرفض الفرض البديل

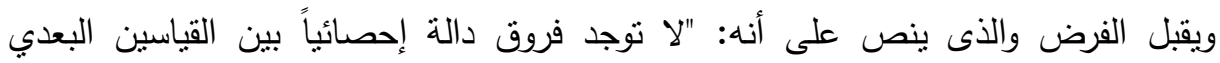
والتتبعي لمقياس الاتجاهات البيئية". وبذلك تتم الإجابة علي التساؤل السابع من أسئلة الدراسة والذي ينص علي "مدي استمرارية تأثثر فعالية الوحدة المقترحة في تتمية المفاهيم البيئية لطلاب الصف الثاني الثانوي؟". 
تفسير النتائج الخاصة بأداء الطلاب فى الاختبار التحصيلي القبلي والبعدي بمستوياته الثلاثة وتفسيرها:

تشير النتائج إلى تفوق طلاب (المجموعة التجريبية الواحدة) التى طبق عليهم الوحدة المقترحة القائمة علي النظرية الاجتماعية لفيجوتسكي، في الاختبار التحصيلي البعدي، ذلك

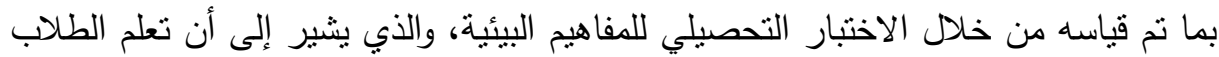
باستخدام الوحدة المقترحة القائمة علي النظرية الاجتماعية لفيجوتسكي، قد ساعد الطلاب علي لفي لئي

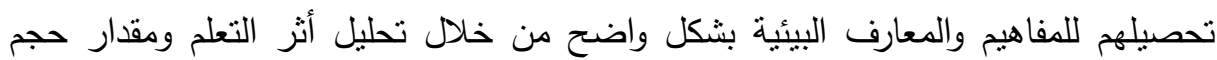

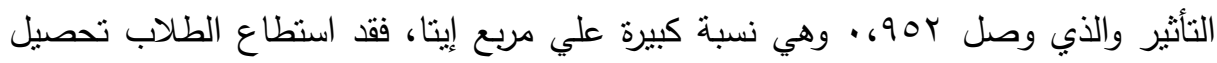

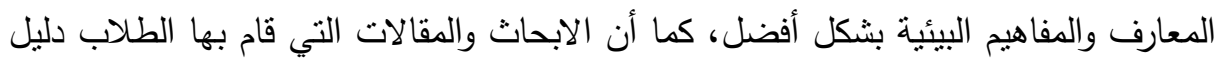

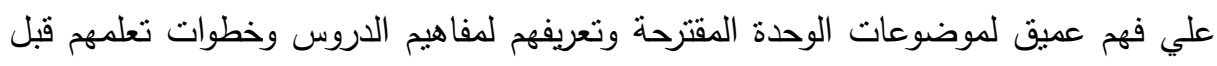

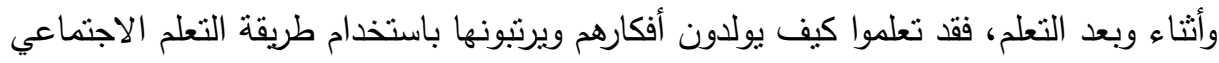
وكتابة الاستجابات للأسئلة المطرحة محل نقاش الحصة فى مراحل الدرس الاربعة، كما تعلموا

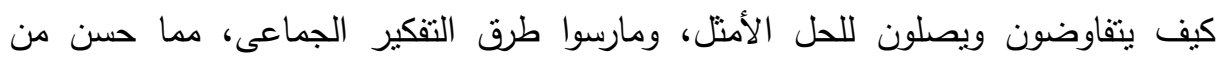
عمليات تفكيرهم خلال تعلم الافكار وانتقالها من خلال المعلم للطالب ومن خلال تعلم القرين من القرين الأخر، كل ذلك ساعد الطلاب على تحصيل جيد للمعارف والمفاهيم البيئية.

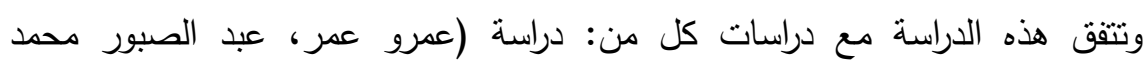

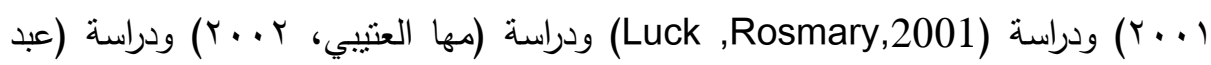

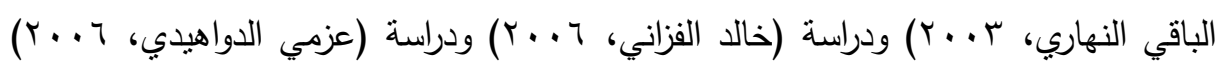
ودراسة (إيمان العباسي، 9 . . ب).

وتتشير النتائج إلى أن فعالية الوحدة المقترحة القائمة علي النظرية البنائية لفيجوتسكي، قد ساعدالطلاب فى تحصل المفاهيم والمعارف البيئية بشكل جيد جداً. برى الباحثون أن العوامل التى أدت إلى زيادة حجم تأثير الوحدة المقترحة القائمة علي النظرية البنائية لفيجوتسكي، قد ترجع إلى أن التعلم الاجتماعي للنظرية البنائية الاجتماعية

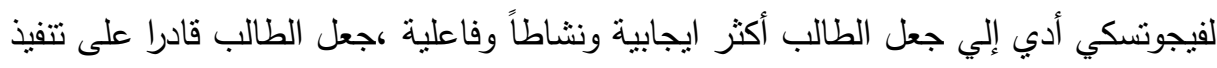

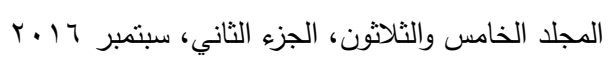


عدد معين من المهام بالتعاون مع الاخرين.(248, Brek, 1997 (لإمكانات الفرد الحالية المزيد من النطور الفكري، قدرة لا نقاس عادة بواسطة إختبارات الذكاء التقليدية". (فابيز

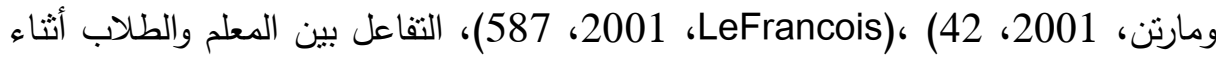
تدريس الوحدة المقترحة، خلق جو تعليمى ساعد على فهم أعمق للمحتوى المقدم والذى هيأ الوسط المناسب لتتمية المفاهيم البيئية. عرض النتائج الخاصة بأداء الطلاب فى مقياس الاتجاهات البيئية القبلي والبعدي وتفسيرها: تتشير النتائج إلى تفوق طلاب (المجموعة التجريبية الواحدة) التى طبق عليهم الوحدة المقترحة القائمة علي النظرية الاجتماعية لفيجوتسكي، في مقياس الاتجاهات البيئية البعدي، ذلك بما تم قياسه من مقياس الاتجاهات البيئية، والذي يشير إلى أن اتجاهات الطلاب عُلت من خلال تدريس الوحدة المقترحة القائمة علي النظرية الاجتماعية لفيجوتسكي، وقد ساعد الطلاب تعديل اتجاهاتهم البيئية بشكل واضح من خلال تحليل أثز التعلم ومقدار حجم التأثير والذي وصل (911،. وهي نسبة كبيرة علي مربع إيتا، فقد استطاع الباحث من تعديل اتجاهات الطلاب بشكل أفضل، كما أن قيام الطلاب بالمشاركة الفعالة في الفصل أثناء تدريس الوحدة المقترحة وكتابة ردود واستجابات للأسئلة المطرحة تجاه البيئية محل نقاش باب

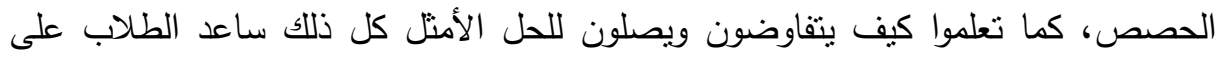
تكوين اتجاه إيجابي نحو البيئة. وتتشير النتائج إلى أن فعالية الوحدة المقترحة القائمة علي

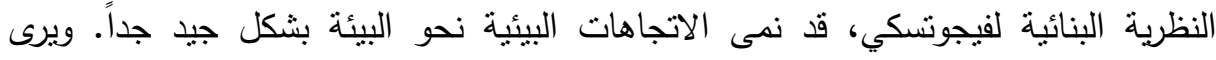

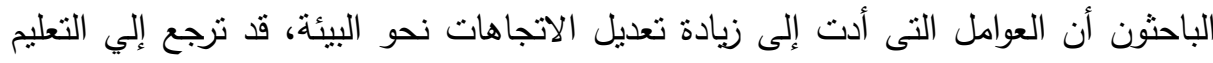

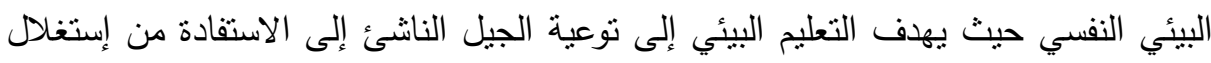
الموارد الطبيعية في البيئة دون المساس بتوازنات أو نشر الملوثات جوًا وبرًا ومياهًا.

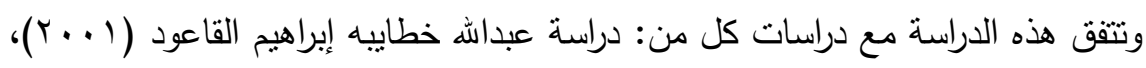

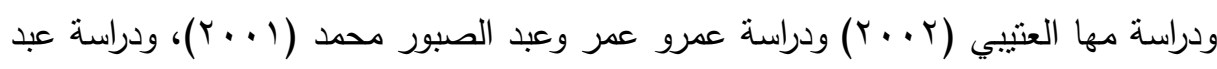

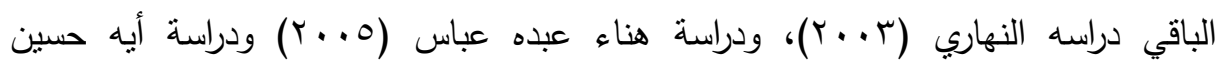


هبة حسين إسماعيل وآخرون

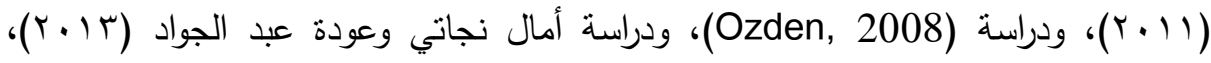

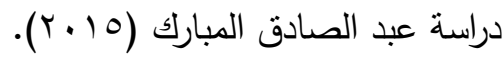

عرض النتائج الخاصة بأداعالطلاب فى الاختبار التحصيلي البعدي والتتبعي

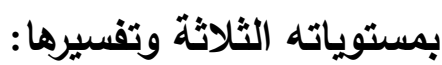

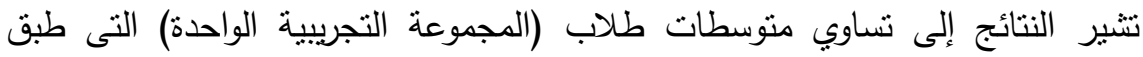
عليهم الوحدة المقترحة القائمة علي النظرية الاجتماعية لفيجوتسكي، في الاختبار التحصيلي

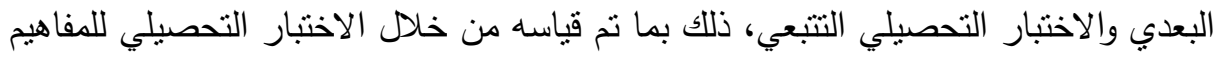
البيئية البعدي والاختبار التحصيلي التتبعي، ومعالجته احصائياً والذي يشير إلى النيا أن استمرار

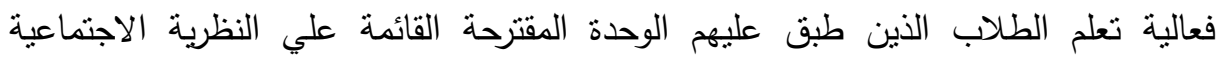

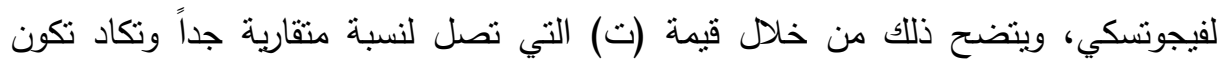

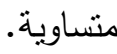

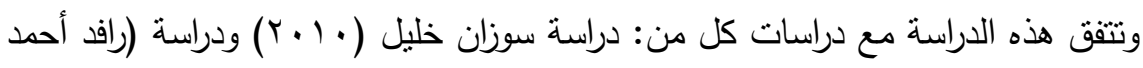

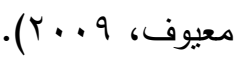

عرض النتائج الخاصة بأداء الطلاب فى مقياس الاتجاهات البيئية البعدي

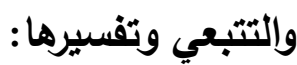

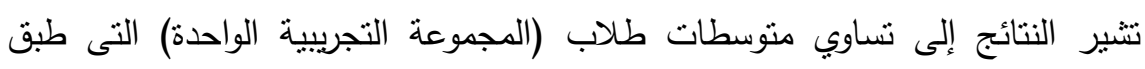

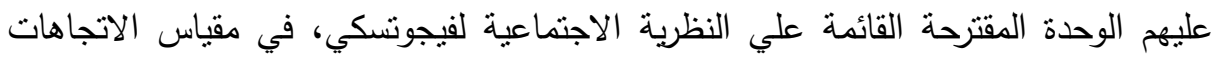

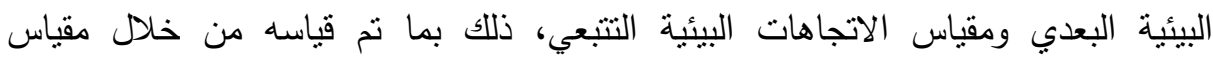

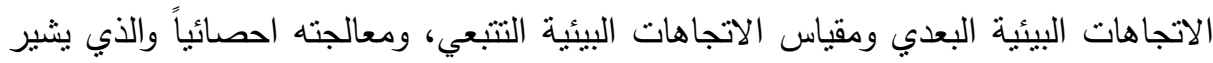

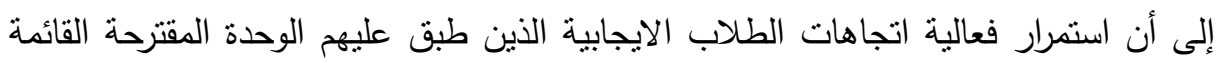

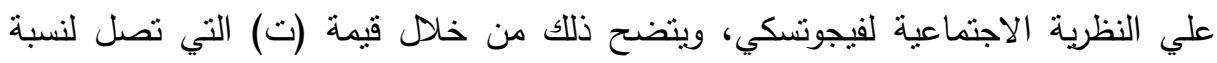

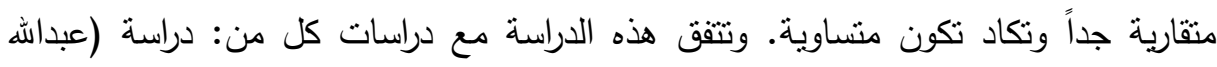

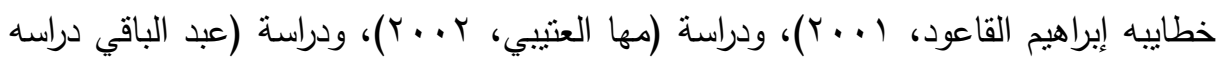




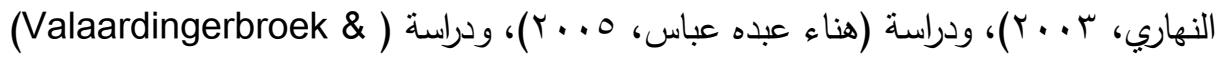

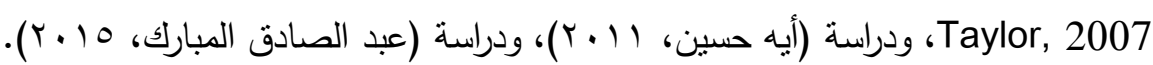

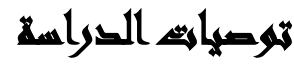

- تضمين المفاهيم البيئية الواردة بقائمة المفاهيم والمرتبطة بعلم النفس الييئي، ضمن مقرر علم النفس لطلاب الصف الثاني الثانوي العام. - دمج الوحدة المقترحة (علم النفس والبيئة) التي نم تطبيقها في الدراسة، في مقرر علم النفس لتتمية المفاهيم والاتجاهات البيئية لاي طلاب الصف الثانه الثانوي العام.

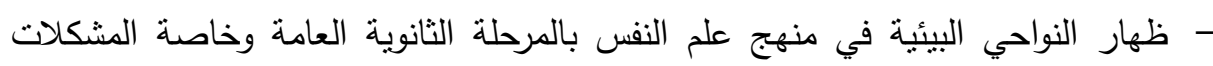

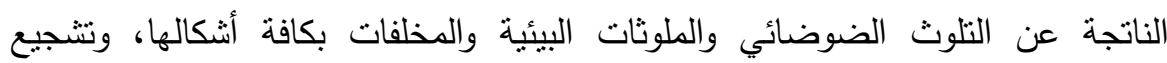

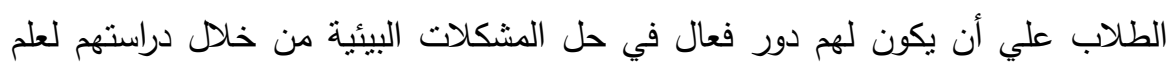
النفس البيئي. - توجيه نظر معلمى علم النفس إلى أهمية استخدام نموذج التعلم البنائي الاجتماعي أو التدريس التبادلي أثناء التدريس داخل حجرة الدراسة ، مما يتيح فرصة أكبر لتعلم فعال

$$
\text { ونشط. }
$$

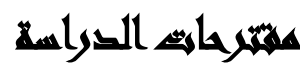

• إجراء مزيد من الدراسات والبحوث حول استخدام استراتيجيات التعلم البنائي الاجتماعي ودراسة تأثنرها فى متغيرات أخرى. • دراسة مقارنة لبعض استراتيجيات التعلم والتعليم النشط - لا سيما استراتيجية الدراسة الحالية

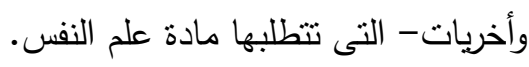
• دراسة فاعلية تدريس مقرر علم النفس البيئي لطلاب المرحلة الاعدادية، كمقرر إثرائي لتتمية السلوك السوي نحو البيئة. 


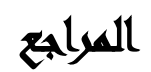

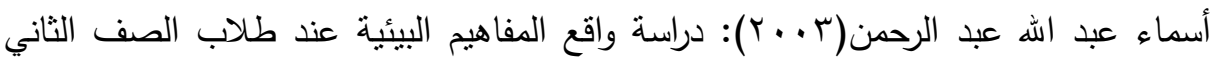

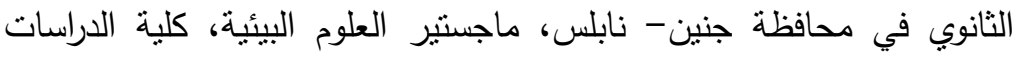

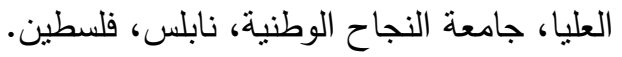

أسماء فؤاد الحجاوي(· ( • ( ): دراسة فعالية برنامج مقترح لتتمية المفاهيم والإتجاهات البيئية

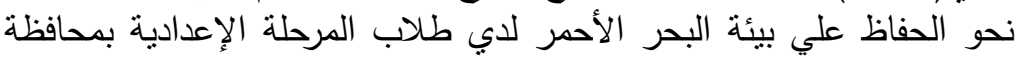

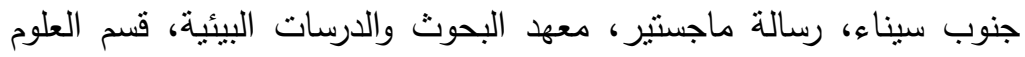
التربوية والإعلام البيئي، جامعة عين شمس.

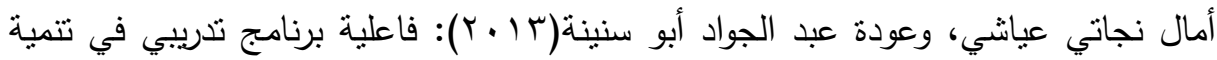

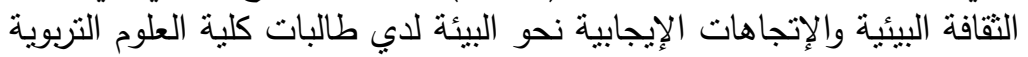

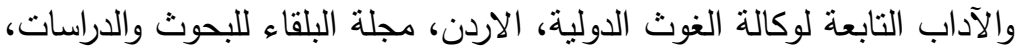

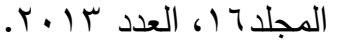

أمين رشيد شيخ محمد(ب ( ب): فاعلية نموذج تدريسي مقترح قائم على النظرية البنائية في

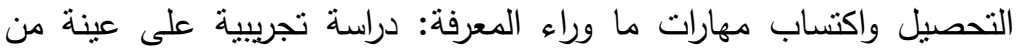

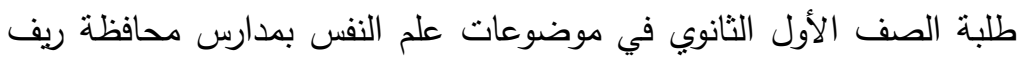

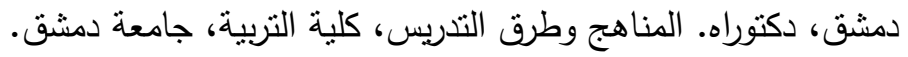

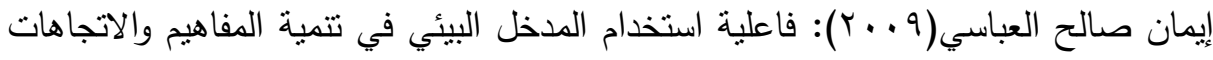

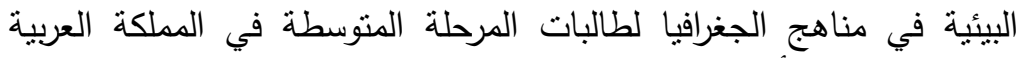

$$
\text { السعودية، جامعة أم القري. }
$$

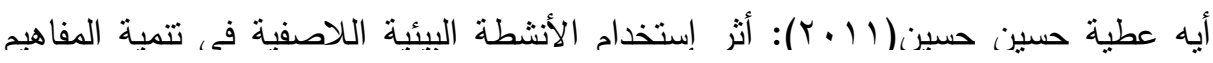

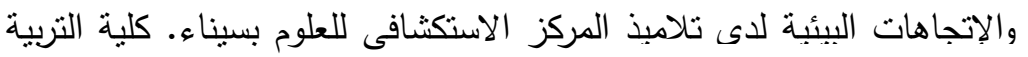
بالعريش، جامعة قناة السويس.

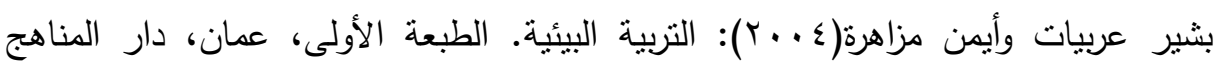
للنشر والتوزيع.

حسن حسين زيتون وكمال عبد الحمبد زيتون(ب . . ץ): التعلم والتدريس من منظور النظرية

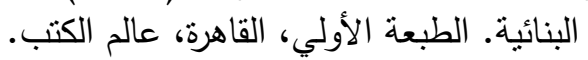

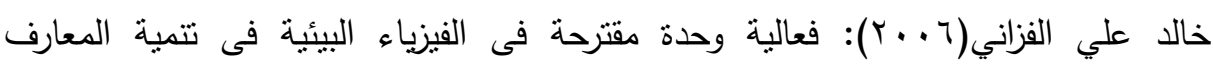
والاتجاهات البيئية لدي طلاب الثانوية التخصصية بليبيا. معهد الدراسات والبحوث البيئية، جامعة عين شمس.

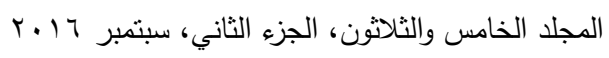




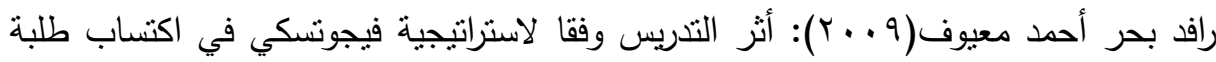

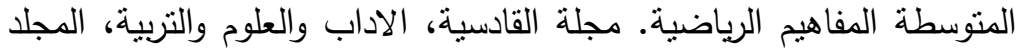

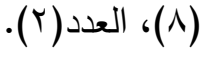

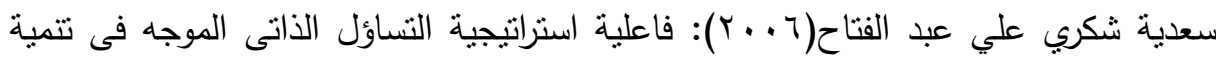

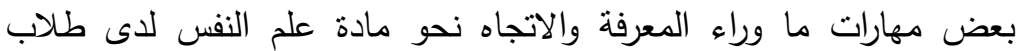
المرحلة الثانوية. رسالة ماجستير ، كلية البنات، جامعة عين شمس.

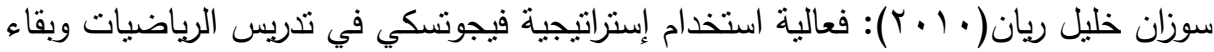

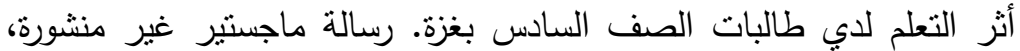

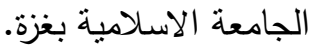

عارف أسعد جمعه(|| + ب): دراسة واقع الدفاهيم التربوية البيئية في مناهج التربية الإسلامية:

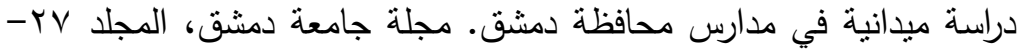
العددالثالث والرابع، كلية التربية، جامعة دمشق.

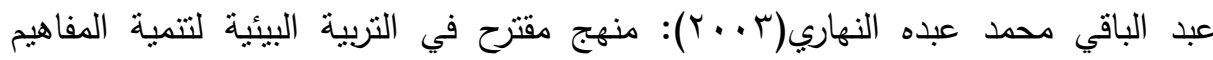
والاتجاهات البيئية لدى طلبة كلية التربية. رسالة دكتوراة، جامعة صنعاء.

عبد الصادق عبد العزيز المبارك(10 • ب): اتجاهات طلاب كليات التربية بجامعة بخت الرضا

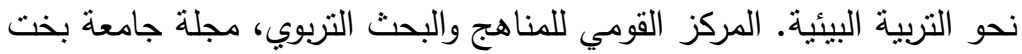

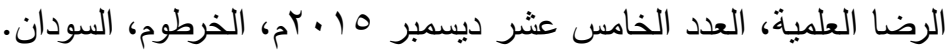

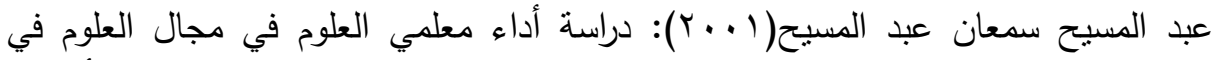

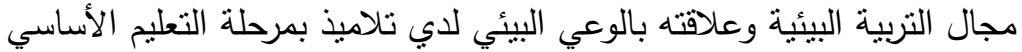

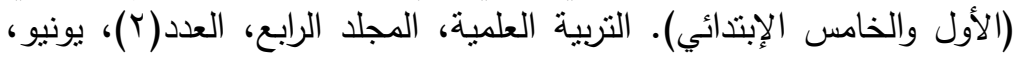
الجمعية المصرية للتربية العلمية.

عبداله خطابية وابراهيم القاعود( ( . . ب): مستوي المعلومات البيئية لدي طلبة جامعة اليرموك

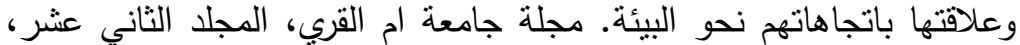

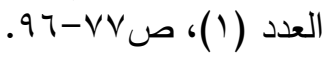

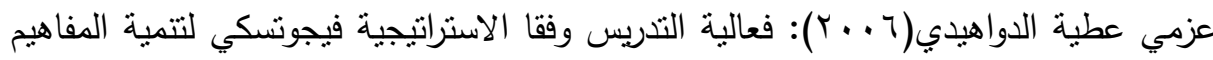

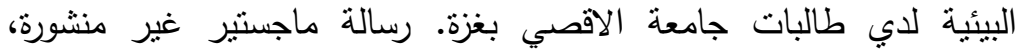

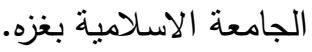


هبة حسين إسماعيل وآخرون

عمرو عمر وعبد الصبور محمد: فاعلية برنامج إرشادي في تعديل بعض الاتجاهات السالبة

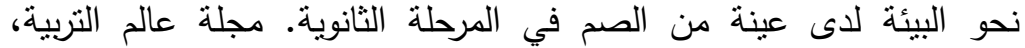

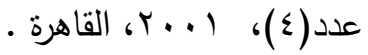

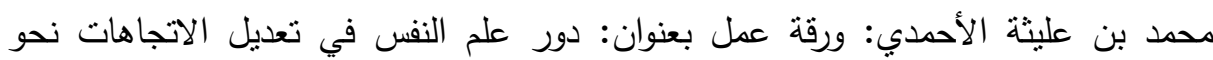

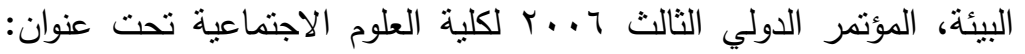

"العلوم الاجتماعية والدراسات البينية من منظور نكاملي" المنعقد في دولة التئة

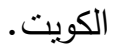

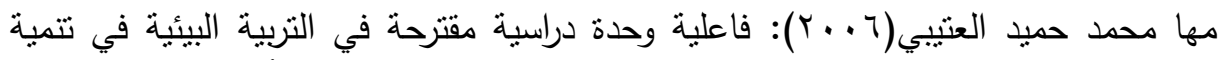

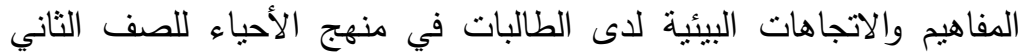

ثانوي علمي في المملكة العربية السعودية.

هناء عبده علي عباس: أثز مقرر التربية البيئية علي اكتساب طلاب كلية التربية ذوبي مهارات

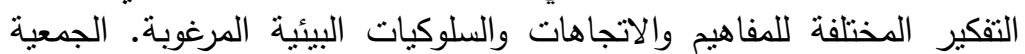

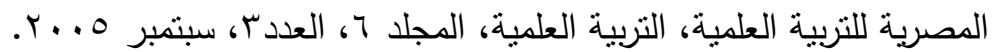

Berk, L. (1997): "Child development" (4th ed.). Boston, Allyn \& Bacon.

Fabes, R., and Martin, C. L. (2001):" Exploring development through childhood. Boston: Allyn \& Bacon.

Guerrero, Maria G.M.De and Villamil,Olga S.(2000):"Activation the ZPD Mutual scaffolding in L2 peer revision the modern language journal, 84، i.

Krantz, doglass (2002): "A study of the impact of environmental educational workshop on teacher's attitude and efficancy" PHD, university of Missouri, Columbia.

LeFrancois, G. (2001): An introduction to child and adolescent development. (9th Ed.). Belmont, CA: Wadsworth/Thomsen

$$
\text { المجلد الخامس والثلاثون، الجزء الثاني، سبتمبر } 7 \text { ا ـ ب }
$$


Luck, Rosmary (2001): Designing children software to ensure productive interactivity through collaboration in the zone of proximal development information technology in childhood education, article 5.

Ozden, M.,(2008): "Environmental Awareness and Attitudes of student teachers: An Empirical research", International Research in Geographical and Environmental Education, 17(1), pp 40-54.

Vlaardingerbroek, B. and Taylor, T. (2007): The environmental knowledge and attitudes of prospective teachers in Lebanon: A Comparative study. International Research in Geographical and Environmental Education, 16(2), pp.120134. 
هبة حسين إسماعيل وآخرون

\title{
A PROPOSED UNIT IN PSYCHOLOGY COURSE BASED ON THE SOCIAL CONSTRUCTIVISM THEORY OF VYGOTSKY FOR DEVELOPMENT ENVIRONMENTAL CONCEPTS AND ATTITUDES FOR GRADE TWO SECONDARY STAGE STUDENT
}

Ismael, Heba, H. ${ }^{(1)}$; Abdel Fatah, Saadia ${ }^{(1)}$ and Osman, W. I. ${ }^{(2)}$ 1) Faculty of Women, Ain Shams University 2) Ministry of Education

\begin{abstract}
The current study aims to investigate the effectiveness of a proposed unit Psychology course based on social constructivism the theory of Vygotsky for developing environmental concepts and attitudes for grade two secondary stage students.

The study applied procedures on a sample included 70 students from the second grade secondary students (literary section), ranging from an average age of 15.5 years old. It has applied achievement test environmental concepts (by the researcher), and the proposed unit (by the researcher), a measure of environmental trends (by the researcher).

The study findings: There is statistically significant differences between the two measurements pre and post test for grades three types (remembering- understanding- application) in favor of (post) the dimensional application. There is no statistically significant differences between the two measurements pre and post to measure environmental attitudes in favor of (post) the dimensional application. There is no statistically significant difference between the two measurements Posttest and iterative test grades three types (remembering, understanding, application). There is no statistically significant difference between the two measurements and dimensional iterative to measure environmental attitudes.
\end{abstract}

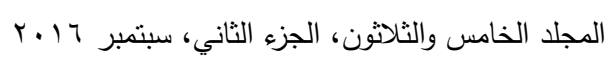

